\title{
On the Temporal Variance of Stratospheric Trace Gas Concentrations
}

\author{
by \\ D. H. Ehhalt, E. P. Röth and U. Schmidt
}

"Universität Essen/Gesamthochschule, D - 4300 Essen, FRG 


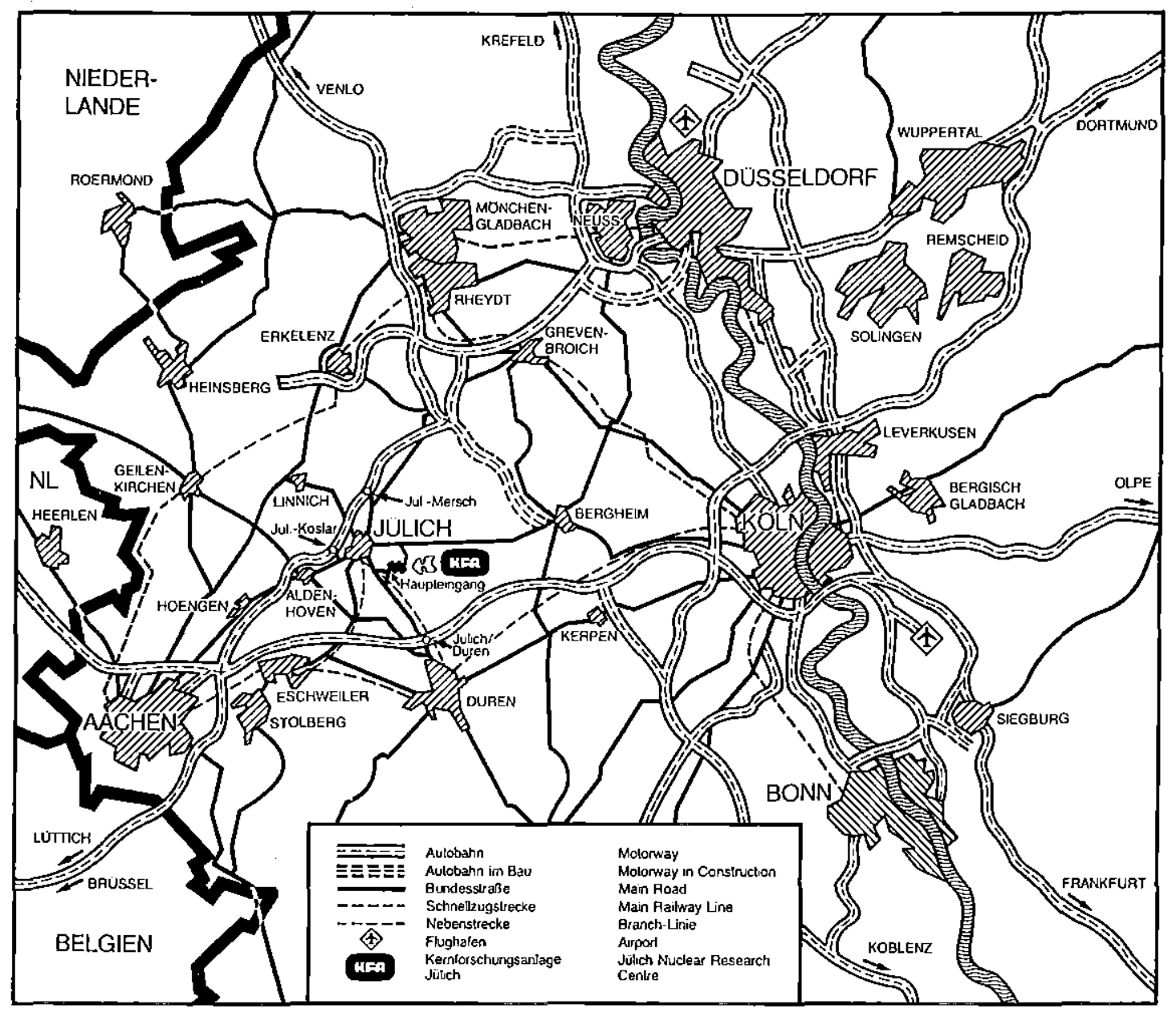

Berichte der Kernforschungsanlage Jülich - Nr. 1836

Institut für Chemie Institut 3: Atmosphärische Chemie Jül - 1836

Zu beziehen durch: ZENTRALBIBLIOTHEK der Kernforschungsanlage Jülich GmbH Postfach 1913 - D-5170 Jülich (Bundesrepublik Deutschland)

Telefon: $02461 / 610 \cdot$ Telex: $833556 \mathrm{kfa} \mathrm{d}$ 
ON THE TEMPORAL VARIANCE OF STRATOSPHERIC TRACE GAS CONCENTRATIONS

\author{
D.H. Ehhalt, E.P. Röth* ${ }^{\star}$, and U. Schmidt \\ Institut für Chemie 3: Atmosphärische Chemie \\ Kernforschungsanlage Jülich GmbH, D-5170 Jülich, FRG \\ *Universität. Essen/Gesamthochschule, D-4300 Essen, FRG
}

\title{
Abstract
}

The relative variances in stratospheric observations of longlived trace gases, $\mathrm{CH}_{4}, \mathrm{~N}_{2} \mathrm{O}, \mathrm{CF}_{2} \mathrm{Cl}_{2}, \mathrm{CFCl}_{3}$, show large differences. These differences are greatly reduced when the local mean standard deviation is normalized to the local vertical gradient. This ratio, called "equivalent displacement height" exhibits a characteristic vertical profile which is very similar for all the longlived trace gases as well as for $0_{3}$. With the help of this ratio it is demonstrated that the variances are essentially due to natural causes, i.e. transport. Using the mixing length hypothes is a theoretical expression for the equivalent displacement height is derived. From it the meridional slope of the mixing surfaces and the mixing length can be calculated as function of the altitude. Additional information is obtained on the variance of that slope. The uncertainty of the measured mean trace gas profiles is defined. 
. 


\section{Introduction}

Much of our faith in current models of stratospheric chemistry rests upon the fact that the model predicted trace gas distributions agree with measured profiles. Agreement is not well defined; it usually means that the model predicted vertical profile follows approximately the shape outlined by the measurements and falls within the range of the data points. Such agreement for a sufficient number of trace gases is said to validate a model. Clearly one would prefer a more quantitative intercomparison of model prediction with experimental observation. In the past this was hampered by a lack of experimental data. The observations were sparse made in different locations and seasons. Consequently the data showed a fair amount of scatter. It was difficult to decide how well the measurements represented the mean stratospheric trace gas distribution and therefore impossible to assign a meaningful uncertainty to the observations.

In the meantime the data base has somewhat improved. For a few trace gases, namely $\mathrm{N}_{2} \mathrm{O}, \mathrm{CH}_{4}, \mathrm{CF}_{2} \mathrm{Cl}_{2}, \mathrm{CFCl}_{3}$ there is a sufficient number of measured vertical profiles so that mean profiles and the corresponding variances can be derived at least for one season and at one location. These gases offer the additional advantage that the techniques for their sampling and measurement are well established and accurate, i.e. the experimental contributions to the observed variance should be as small as currently possible for any trace gas. Moreover simultaneous measurements are available for these gases which should help to corroborate the findings from an individual species and reduce the possible sources of error. Finally their stratospheric life cycle is relatively simple: All these gases originate at the earth's surface and have relatively long tropospheric lifetimes. Thus they are approximately uniformly distributed in the troposphere and the tropopause constitutes a surface of nearly constant mixing ratio. The 
stratospheric chemistry acts on $1 y$ to destroy these gases - at rates which in crease with altitude. This results in a mean distribution with a monotonic decrease in mixing ratio with altitude at all latitudes - a most simple case.

In the following we will investigate the stratospheric variance of these trace gases and attempt to identify its cause. At that point we will also investigate what information may be contained in the observed variances. Finally we will attempt to define the uncertainty of the mean profile of these gases. For comparison $\mathrm{O}_{3}$ and the potential temperature, $\theta$, will also be treated. 


\section{Evaluation of the variance and its altitude dependence}

For the present analyses we use data from 10 balloon flights over Southern France $\left(43^{\circ}-44^{\circ} \mathrm{N}\right)$ during which simultaneous vertical profiles of $\mathrm{CH}_{4}, \mathrm{~N}_{2} \mathrm{O}$, $\mathrm{CFCl}_{3}$ and $\mathrm{CF}_{2} \mathrm{Cl}_{2}$ were obtained. The flights were made at situations of weak stratospheric winds mostly in June, on two occasions in September, in the years betwen 1977 and 1979. The experiments were a joint effort between the Max-PlanckInstitute for Aeronomy, Lindau, the Max-Planck-Institute for Chemistry in Mainz, and the Institute of Atmospheric Chemistry at the KFA Jiilich. To exclude any variance resulting from differences in the absolute calibrations between the laboratories we will consider our own measurements only. The measurements and techniques used were described in several publications (Ehhalt, 1980; Fabian et a1., 1979, 1981). The data are also available in tabular form (Volz et al., 1981).

The vertical profiles of $\mathrm{CH}_{4}, \mathrm{~N}_{2} \mathrm{O}, \mathrm{CF}_{2} \mathrm{Cl}_{2}$ and $\mathrm{CFCl}_{3}$ measured over Southern France are summarized in Figure 1. To remove the variance due to the secular increase of $7.5 \% / \mathrm{yr}$ in $\mathrm{CF}_{2} \mathrm{Cl}_{2}$ and $8 \% / \mathrm{yr}$ in $\mathrm{CFCl}_{3}$ concentrations the CFM data were all normalized to the same date: June 1979. It should be noted that the vertical scale is an approximate altitude. The primary quantity measured during the flights is the ambient pressure which was converted to the geometric altitude using the US Standard Atmosphere (1976).

The data exhibit the well known decrease with altitude. The vertical gradient is a function of the stratospheric lifetime of the species and increases substantially between the longest lived species, $\mathrm{CH}_{4}$ and the shortest lived, $\mathrm{CFCl}_{3}$. The main point of interest here is the scatter in the individual measurements. Clearly the relative scatter increases with altitude for each species. Secondly the relative scatter is quite different for the various species increasing in 
the order $\mathrm{CH}_{4}, \mathrm{~N}_{2} \mathrm{O}, \mathrm{CF}_{2} \mathrm{Cl}_{2}, \mathrm{CFCl}_{3}$, i.e. increasing with the vertical gradient of the species. Thirdly the scatter is much larger than the analytical precision given by the authors which ranges from $2 \%$ to $5 \%$ increasing to $50 \%$ at the detection limit (Fabian et a1., 1979; Volz et al., 1981).

There are not enough data points to determine the frequency distribution with certainty even when the data from all altitudes are normalized to the respective standard deviations and superimposed. Both, a normal or a log normal distribution seem equally likely, although in principle a log normal distribution would be more plausible.

To obtain a more quantitative measure of the scatter we calculated the mean and the mean standard deviation as a function of altitude. Because of the 1imited number of data this was done in form of a running mean using a $5 \mathrm{~km}$ interval and a step height of $1 \mathrm{~km}$. To allow for the vertical gradient, an exponential regression line was fitted to the data of each $5 \mathrm{~km}$ interval. The mean standard deviation, $\sigma_{j}$, in the ith interval was calculated as

$$
\sigma_{i}^{2}=\frac{1}{n_{j}-2} \sum_{j}\left(M\left(z_{j}\right)-m_{j}\left(z_{j}\right)\right)^{2}
$$

where $n_{i}$ are the number of data points, $M\left(z_{j}\right)$ are the measured mixing ratios, $m_{i}\left(z_{j}\right)$ the mixing ratios calculated from the regression line in the ith interval. The $z_{j}$ are the altitudes of the measurements covered by the $i$ th interval. The resulting mean mixing ratios and standard deviations are also shown in $F_{i-}$ gure 1 . Obviously only every 5 th such point is obtained in a statistically independent manner. We observe that, the relative standard deviation of $\mathrm{CH}_{4}$ increases from about $\pm 5 \%$ at $15 \mathrm{~km}$ to about $\pm 20 \%$ at $30 \mathrm{~km}$, those of $\mathrm{N}_{2} \mathrm{O}$ and $\mathrm{CF}_{2} \mathrm{Cl}_{2}$ from $\pm 5 \%$ to $\pm 40 \%$, and that of $\mathrm{CFCl}_{3}$ from $\pm 12 \%$ to a factor of \pm 2.5 at $30 \mathrm{~km}$. Only, in the latter case the mixing ratios found at $30 \mathrm{~km}$ are close to the limit of detection. 


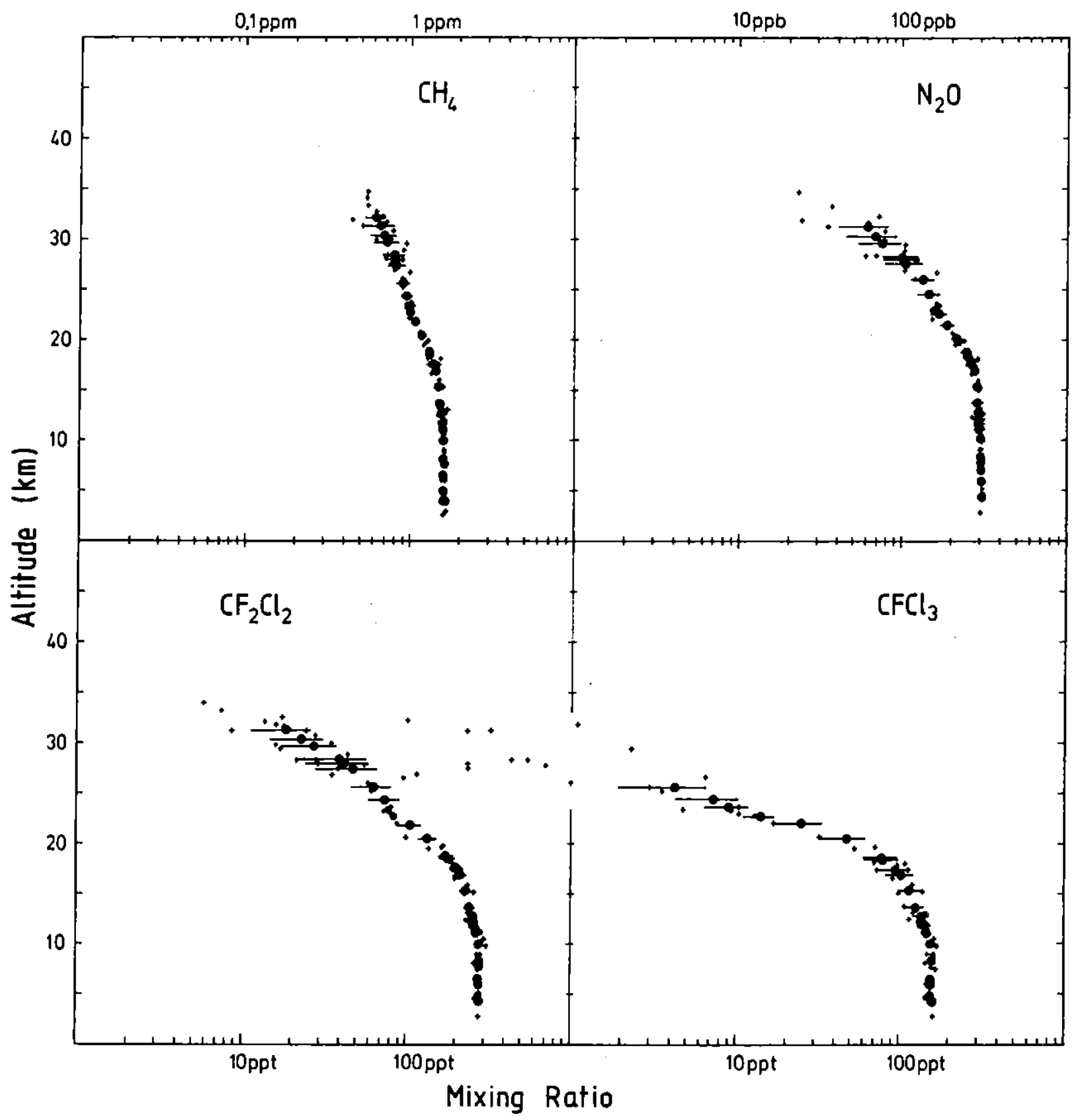

Figure 1 Vertical profiles of $\mathrm{CH}_{4}, \mathrm{~N}_{2} \mathrm{O}, \mathrm{CF}_{2} \mathrm{Cl}_{2}$, and $\mathrm{CFCl}_{3}$ over Southern France $\left(43^{\circ}-44^{\circ} \mathrm{N}\right.$ latitude). The crosses represent the individual measurements, the full dots a $5 \mathrm{~km}$ running average. The bars indicate the mean standard deviation of the running average. 
Clearly for all these trace gases the observed relative mean standard deviation increases strongly, a factor 3 to 10 between $15 \mathrm{~km}$ and $30 \mathrm{~km}$ altitude. At the higher altitude where the respective gradients differ more widely the mean standard deviations of the various trace gases differ by one order of magnitude; at the lower altitude where the gradients are small and more comparable, the relative mean standard variations differ only by a factor of 2 . But even there the observed mean standard deviation exceeds greatly the precision of the analytical procedure as determined by independent tests in the laboratory (Volz et al., 1981).

\subsection{The equivalent displacement height}

There are several sources of noise and error, both experimental and natural, which could contribute to the observed variances. Some of them can be excluded by adopting a treatment of the variance which is suggested by the data themseives: It has been observed in the foregoing that the size of mean standard deviation appears to be correlated to the strength of the vertical gradient. This, incidentally, would be the case for natural fluctuations (see below). We will therefore normalize the local mean standard deviation to the local gradient:

$$
\Delta=\sigma(z) / \frac{\partial M}{\partial z}
$$

In this way the variance in concentration is expressed as variance in altitude. The resulting entity $\Delta$, which represents the corresponding mean vertical deviation, will be called "equivalent displacement height" for reasons which will become clearer below. There are several ways in which $\Delta$ can be derived. We chose the following. First, to obtain a smooth, average vertical gradient of the mix- 


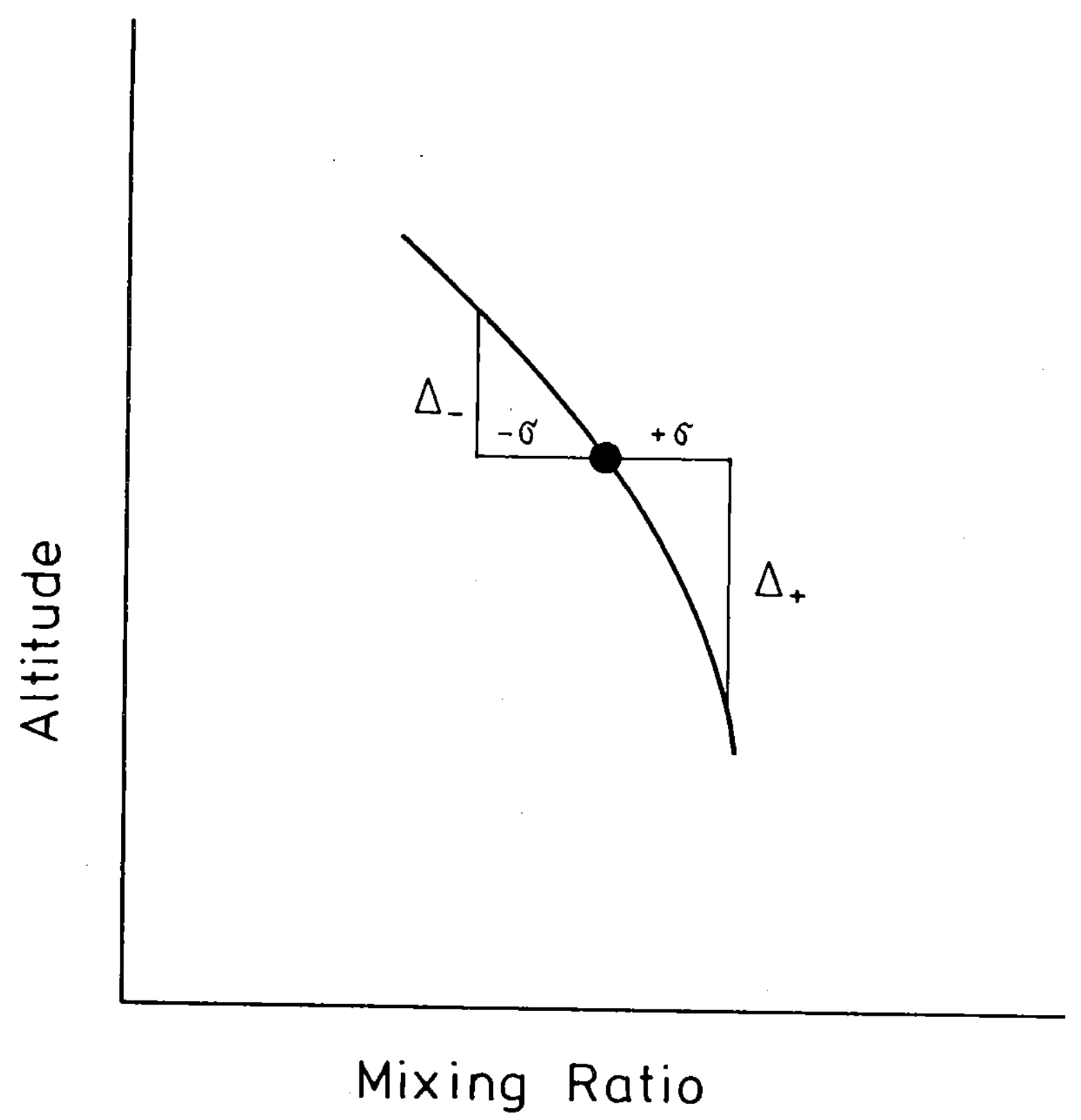

Figure 2 Geometrical definition of the equivalent displacement height, $\Delta$. 
ing ratio, $\partial M / \partial z$, we fitted a smooth curve of the type $M=M_{0} \exp \left(-a z-b z^{2}\right)$ to the data above the tropopause. This exponential function allows enough curvature to represent the data quite well. The resulting functions were:

$$
\begin{aligned}
& \mathrm{CH}_{4}: \quad \lg \mathrm{M}(\mathrm{z})=-5.78-1.31 \times 10^{-2}(z-12)-3.90 \times 10^{-4}(z-12)^{2} \\
& \mathrm{~N}_{2} \mathrm{O}: \lg \mathrm{M}(\mathrm{z})=-6.52+1.17 \times 10^{-4}(z-12)-1.88 \times 10^{-3}(z-12)^{2} \\
& \mathrm{CF}_{2} \mathrm{Cl}_{2}: \lg \mathrm{M}(\mathrm{z})=-9.57-1.47 \times 10^{-2}(z-12)-2.33 \times 10^{-3}(z-12)^{2} \\
& \mathrm{CFCl}_{3}: \lg \mathrm{M}(\mathrm{z})=-9.79-1.93 \times 10^{-2}(z-11)-5.69 \times 10^{-3}(z-11)^{2} .
\end{aligned}
$$

Below the tropopause the data are fitted by a straight line. As Figure 2 illustrates, $\Delta_{j}$ is then determined as the difference between the aititude $z_{j}$, at which the curves $(3 a)-(3 d)$ assume the mean values $\bar{M}\left(z_{j}\right)$, and the altitudes, at which they assume $\bar{M}\left(z_{i}\right) \pm \sigma_{i}$. In principle one obtains two different values for the equivalent displacement height, $\Delta_{+}$and $\Delta_{-}$, because of the curvature of the mixing ratio profiles. The difference between $\Delta_{+}$and $\Delta_{-}$, however, is usually small except around the tropopause where the vertical gradients become very shallow and the two differently fitted sections meet. The $\Delta$ given in the following is the average between $\Delta_{-}$and $\Delta_{+}$. In this way $\Delta(z)$ approximates $\sigma(z) /$ $\partial M(z) / \partial z$ most closely. The uncertainty of $\Delta$ such derived can also be estimated. In the stratosphere it is dominated by the uncertainty in the mean standard deviation, $\sigma$; in most cases the error in the slope gives only a minor contribution. With the assumption that the data points show a gaussian distribution which is reasonably well fulfilled as indicated above, the estimated error of $\sigma_{i}$ is $1 / \sqrt{2\left(n_{i}-1\right)} . n_{i}$ is the number of data points in the $5 \mathrm{~km}$ interval of the running average. Thus the accuracy with which $\sigma_{i}$ and therefore $\Delta_{i}$ can be determined is essentially a function of the number of available measurements:

The $\triangle$-values for $\mathrm{CH}_{4}, \mathrm{~N}_{2} \mathrm{O}, \mathrm{CF}_{2} \mathrm{Cl}_{2}$ and $\mathrm{CFCl}_{3}$ are intercompared in Figure 3. Since they are based on the $\sigma$-values from Figure 1 , the $\Delta$ values also represent a running average and only every 5 th point is statistically independent. The pre- 


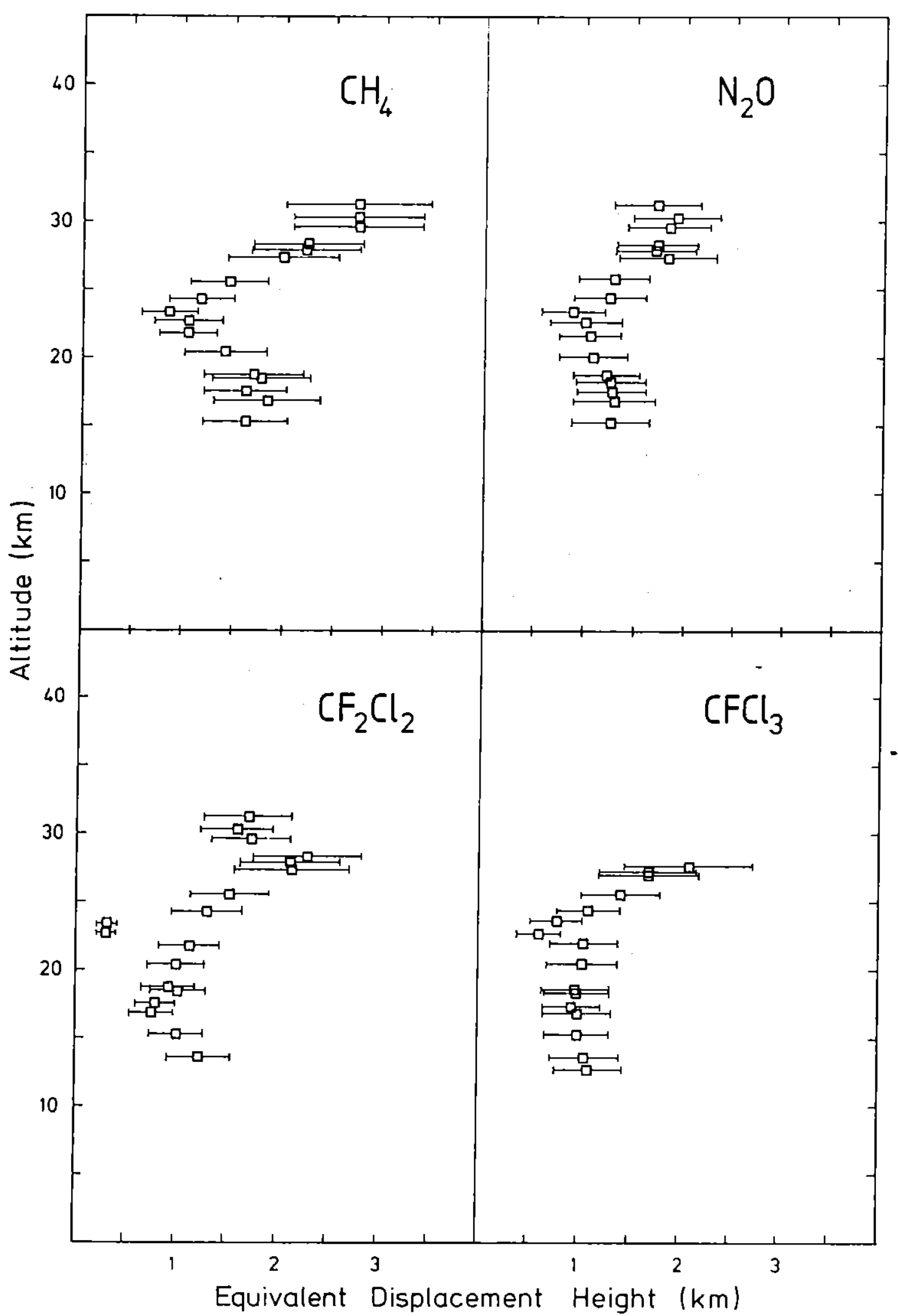

Figure 3 Vertical profiles of the equivalent displacement height, $\Delta$, for the mixing ratio profiles shown in Figure 1 . The bars represent the estimated uncertainty of the $\Delta$-values. 
sentation in Figure 3 is limited to the altitude range between about 15 and $30 \mathrm{~km}$. Above $30 \mathrm{~km}$ the data become sparse. Moreover not all profiles reach those altitudes which could have led to apparent reduction in the observed variance. Below $15 \mathrm{~km}$ altitude $\Delta_{-}$and $\Delta_{+}$are increasingly separated by a wide margin and $\Delta$ is not as well defined as in the altitudes above. However $\Delta_{+}$and $\Delta_{-}$continue to increase towards lower stratospheric altitudes.

Considering the vast differences between the $\sigma$-values of the different trace gases, the profiles of the $\Delta$-values are astonishingly close. They all show a similar pattern: Slightly higher $\Delta$-values of 1 to $1.5 \mathrm{~km}$ at $15 \mathrm{~km}$ altitudes; a decrease with altitude to $\Delta$-values between 0.5 and $1 \mathrm{~km}$ at a minimum around $24 \mathrm{~km}$; an increase above $25 \mathrm{~km}$ altitude to a $\Delta$-value of 2 to $3 \mathrm{~km}$ at $30 \mathrm{~km}$ altitude. At any given altitude the $\Delta$-values from the different trace gases agree within the uncertainty ranges. On the other hand the uncertainties in the $\Delta$-values are sufficiently large, such that this pattern is just barely significant for some of the trace gases.

To convince ourselves that this agreement is not coincidental or an artifact of the present measurements, we briefly investigate the $\Delta$-values derived from other data sets available from the literature. As a first example we consider 13 profiles of the $\mathrm{N}_{2} \mathrm{O}$ and $\mathrm{CF}_{2} \mathrm{Cl}_{2}$ mixing ratio measured by Goldan et al. (1980) over Laramie, Wyoming, USA, at $41^{\circ} \mathrm{N}$ latitude. The latter, although collected in the years 1976 and 1978 are also normalized to June 1979. These profiles are comparable in latitude to our data which were obtained at $43^{\circ} \mathrm{N}$ latitude. They are, however, more or less uniformiy distributed throughout the year, whereas our flights clustered in the month of June. Nevertheless the mean profiles of the mixing ratio over Laramie compare very favorably with those shown in Figure 1 (cf. Ehhalt, 1980). The $\Delta$-profiles derived from these data are shown in Figure 4. 


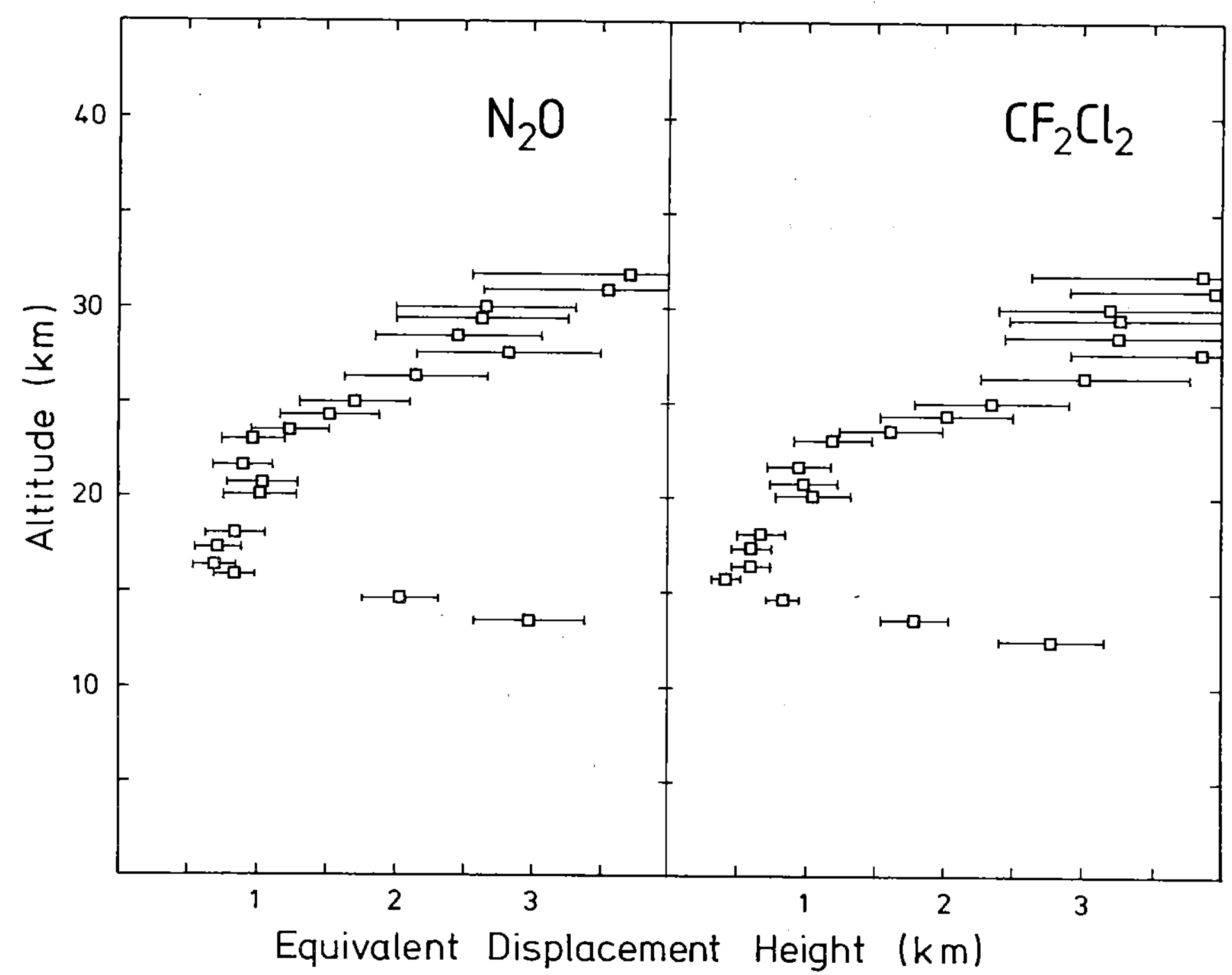

Figure 4 Equivalent displacement height profiles from mixing ratio profiles of $\mathrm{N}_{2} \mathrm{O}$ and $\mathrm{CF}_{2} \mathrm{Cl}_{2}$ measured over Laramie, Wyo., $41^{\circ} \mathrm{N}$ Tatitude (Goldan et al., 1980). 
They show the features found in Figure 3 even more pronounced. The increase above $25 \mathrm{~km}$ altitude is steeper leading to $\Delta$-values of around $3 \mathrm{~km}$ at $30 \mathrm{~km}$ altitude. The minimum is deeper. It is also broadec extending and $23 \mathrm{~km}$ altitude and reaches its lowest values at $16 \mathrm{~km}$ altitude whereas the $\Delta$-values for $\mathrm{CH}_{4}$ and $\mathrm{N}_{2} \mathrm{O}$ over Southern France reached their lowest values at $23 \mathrm{~km}$. However when superimposed, these and our $\Delta$-values agree within the error bars (cf. Figure 8).

\subsection{The equivalent displacement height for ozone}

The second example is $0_{3}$. Its stratospheric distribution has been studied in much more detail than those of the longlived trace gases. At the same time its stratospheric chemistry is much more intricate. It is both produced and destroyed within the stratosphere. Thus its source and sink distribution is completely different from that of the longlived trace gases resulting in a more complicated concentration distribution. In particular the vertical profile of $0_{3}$ mixing ratio shows a strong increase between the tropopause and $30 \mathrm{~km}$ altitude where it reaches a maximum of about $10 \mathrm{ppm}$ (cf. Figure 5 ). In addition it is measured by a completely different technique. A priori there appears to be little reason, analytical or chemical, that the variance in $0_{3}$ concentrations should be related to that of the longlived trace gases. Yet this is the case.

Figure 5 displays two sets of five $0_{3}$ profiles measured by Attmannspacher (1980, 1981) in July 1979 and June 1980 over Hohenpeissenberg, Southern Germany (48 N). The data are therefore comparable in latitude and season with the measurements of the longlived trace gases. As before variance and average $0_{3}$ profiles were calculated using a running mean with a $5 \mathrm{~km}$ height interval. The results are also shown in Figure 5 . In the case of $0_{3}$ the relative variance is largest around and above the tropopause, a fact which had already been noted by Ditsch 


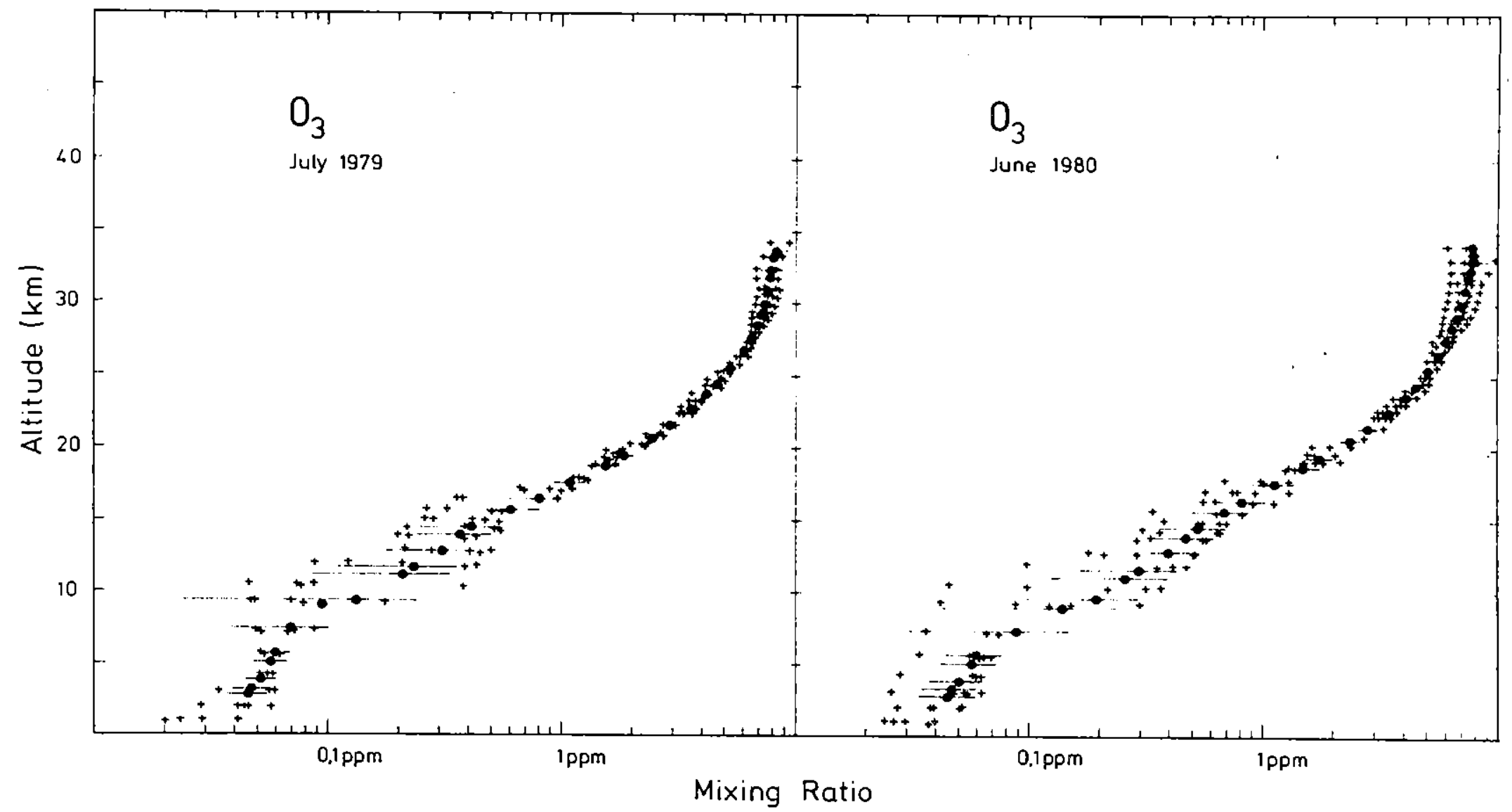

Figure 5 Vertical profiles of $\mathrm{O}_{3}$ over Hohenpeißenberg $48^{\circ} \mathrm{N}$ latitude, Germany (Attmannspacher, 1980, 1981). The crosses represent the individual measurements from 5 flights, the full dots

a $5 \mathrm{~km}$ running average. The bars indicate the mean standard deviation of the running average. 
(1969). In the height interval between the tropopause and $25 \mathrm{~km}$ the variance decreases markedly with altitude quite in contrast to the variance for the longlived trace gases. The corresponding $\Delta$-profiles for $\mathrm{O}_{3}$ are shown in Figure 6 . They are smoother and have smaller error bars because the balloon borne electrochemical sondes which were used for $\mathrm{O}_{3}$ analysis provided a nearly continuous. readout and many more data points were available for $\mathrm{O}_{3}$ than for the long lived trace gases. Also, since the gradient of the $0_{3}$ mixing ratio profile is steep around the tropopause, the $\Delta$-values around the tropopause are well characterized. Most important, however, the profiles of the equivalent displacement height for $0_{3}$ are in excellent agreement with the ones for longlived trace gases in Figures 3 and 4.

During the $\mathrm{O}_{3}$ flights the temperature was also measured. Thus the geometric altitude and the potential temperature for these flights can be determined, and it is possible to calculate the $\Delta$-values for $\mathrm{O}_{3}$ with respect to true altitude or constant potential temperature, rather than constant pressure (approximate altitude) as has been done in Figures 3 to 6 . Doing that reveals only minimal differences to Figure 6 which are well within the error range of the $\Delta$-values.

We have also examined a number of $\mathrm{O}_{3}$ concentration and variance profiles from other seasons. The resulting $\Delta$-profiles, a 11 , showed the same pattern below $30 \mathrm{~km}$ altitude. In a few instances a somewhat different pattern is suggested for altitudes above $30 \mathrm{~km}$. They show a decrease in $\Delta$-value with altitude above that level.

\subsection{The equivalent displacement height for the potential temperature}

Since the temperature was also measured during the $0_{3}$ flights (Attmannspacher, 1980, 1981) it is possible to extend the concept of equivalent displacement 


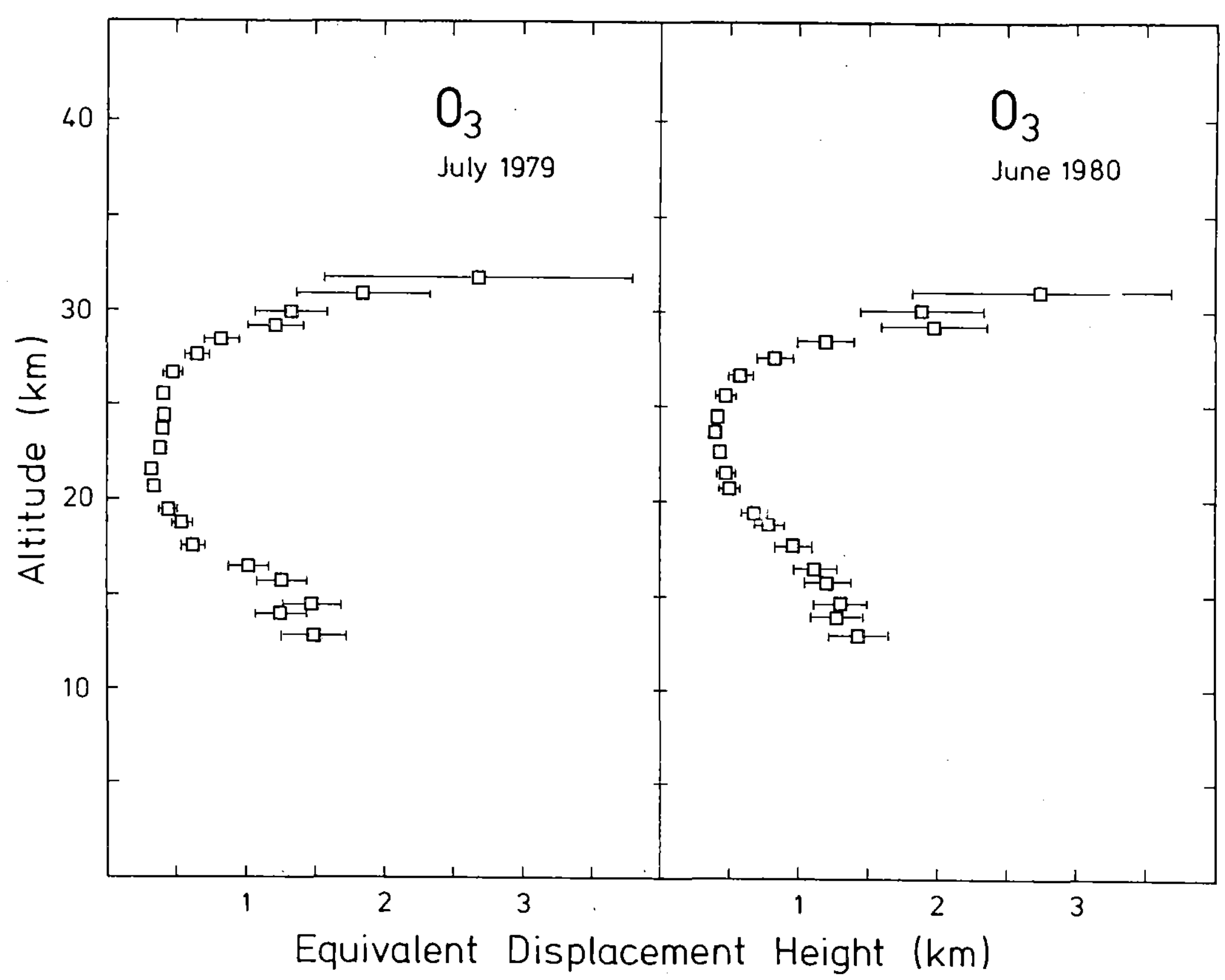

Figure 6 Vertical profiles of the equivalent displacement height from the $0_{3}$ profiles shown in Figure 5. 
height to the variance in the measured temperature profiles. This was done in terms of the potential temperature, $\theta=T \cdot\left(p_{0} / p\right)^{k}$, because the latter is conserved during vertical displacements. T is the temperature, $p, p_{0}$ is the pressure at altitude and at the earth's surface respectiveiy, $K=0.286$. The profile of the average temperature and its mean standard deviation for July 1979 is shown in Figure 7 .

As before, the vertical scale is the approximate altitude derived from the measured ambient pressure. From these data, the mean standard deviation, $\sigma_{\theta}$, and the gradient, $\frac{\partial \theta}{\partial z}$, of the potential temperature were calculated. The right hand panel in Figure 7 presents the profile of the equivalent displacement height for the potential temperature, $\Delta_{\theta}=\sigma_{\theta} / \frac{\partial \theta}{\partial z}$. We note that this profile has the same shape as those of the trace gases. However the absolute values of the equivalent displacement heights are about a factor of 10 lower.

\subsection{The contribution of the experimental uncertainties to the equivalent dis-} placement height of the long lived trace gases

Expressing the variance of the mixing ratio profiles in terms of equivalent displacement height results in a significant simplification: The vertical profiles of that parameter exhibit a consistent pattern for all trace gases investigated. This is once more verified by superimposing the equivalent displacement heights for $\mathrm{CH}_{4}, \mathrm{~N}_{2} \mathrm{O}, \mathrm{CF}_{2} \mathrm{Cl}_{2}, \mathrm{CFCl}_{3}$ and $\mathrm{O}_{3}$ from Figures 3,4,6 in one graph, Figure 8 . Figure 8 demonstrates that the $\Delta$-profiles of all these trace species not only have the same pattern, a $\mathrm{C}$-shape, but that within the error bars the $\Delta$ agree in absolute value at each altitude - with the possible exception of the $\Delta$-values for $O_{3}$ at 20 and $25 \mathrm{~km}$ altitude which seem to fall significantly below the others. This common behavior strongly suggests a common cause for the variance of the various species. Such a suggestion does not by 


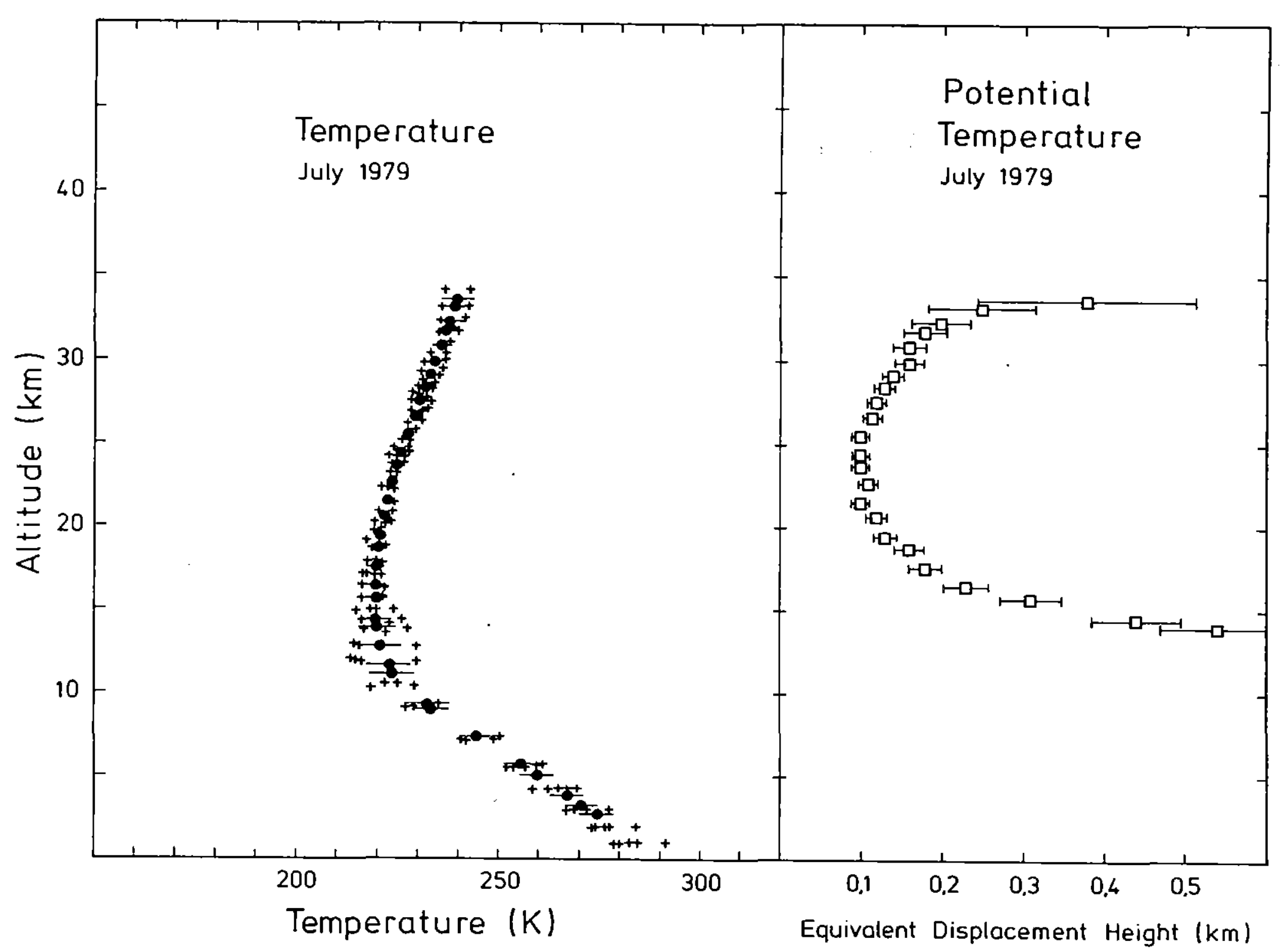

Figure 7 Vertical profiles of the temperature and the resulting equivalent displacement height of the potential temperature, $\Delta_{\theta}$, over Hohenpeißenberg, $48^{\circ} \mathrm{N}$ (Attmannspacher, 1980). The crosses represent the individual measurements from 5 flights, the full dots a $5 \mathrm{~km}$ running average. The bars indicate the mean standard deviation of the running average and the uncertainty in the $\Delta$-value respectively. 
itself exclude experimental errors as cause of the variance, but it strongly limits the number of possible error sources. It excludes errors in the analytical procedures, because the different longlived trace gases are measured by different gaschromatographic techniques using different instruments with detection limits which are at least one order of magnitude below the lowest concentration observed - with the exception of $\mathrm{CFCl}_{3}$. It excludes fractionation during sampling or sample transfer because the molecular mass and boiling points of these gases span a wide range. Thus, if fractionation occurred some gases would be affected little others strongly. It excludes contamination by walls or the leakage of tropospheric air, because the concentrations of the measured species differ greatly and the concentration differences between stratospheric air and tropospheric air varies widely among them. All these and some other sources of experimental error, though certainly real, would influence the various trace gases to greatly different degrees. They cannot cause the similar and systematic variation of the variance of the trace gases as expressed by the profiles of the $\Delta$-values. This is in keeping with the above mentioned fact that the laboratory tests of instrumental reproducibility of sampling, storage and analysis gave a much smaller variance than observed for the actual stratospheric samples.

In fact the only experimental factor which could influence the $\Delta$-values of the different species in the observed uniform way would be a large error in the measurement of the ambient pressure and thus of the sampling altitude. Such large errors in the pressure measurements seem unilkely even for the highest altitudes reached here. The ambient pressure measurements during our flights were provided by the "CNES" balloon launch facility. It employed two Penny and Giles pressure transducers (type TP $71 \mathrm{~A} / 200$ ) with ranges from $1034 \mathrm{mb}$ to $10 \mathrm{mb}$ and from $69 \mathrm{mb}$ to $0 \mathrm{mb}$. The lower range transducer had an uncertainty of $\pm 0.7 \mathrm{mb}$. 


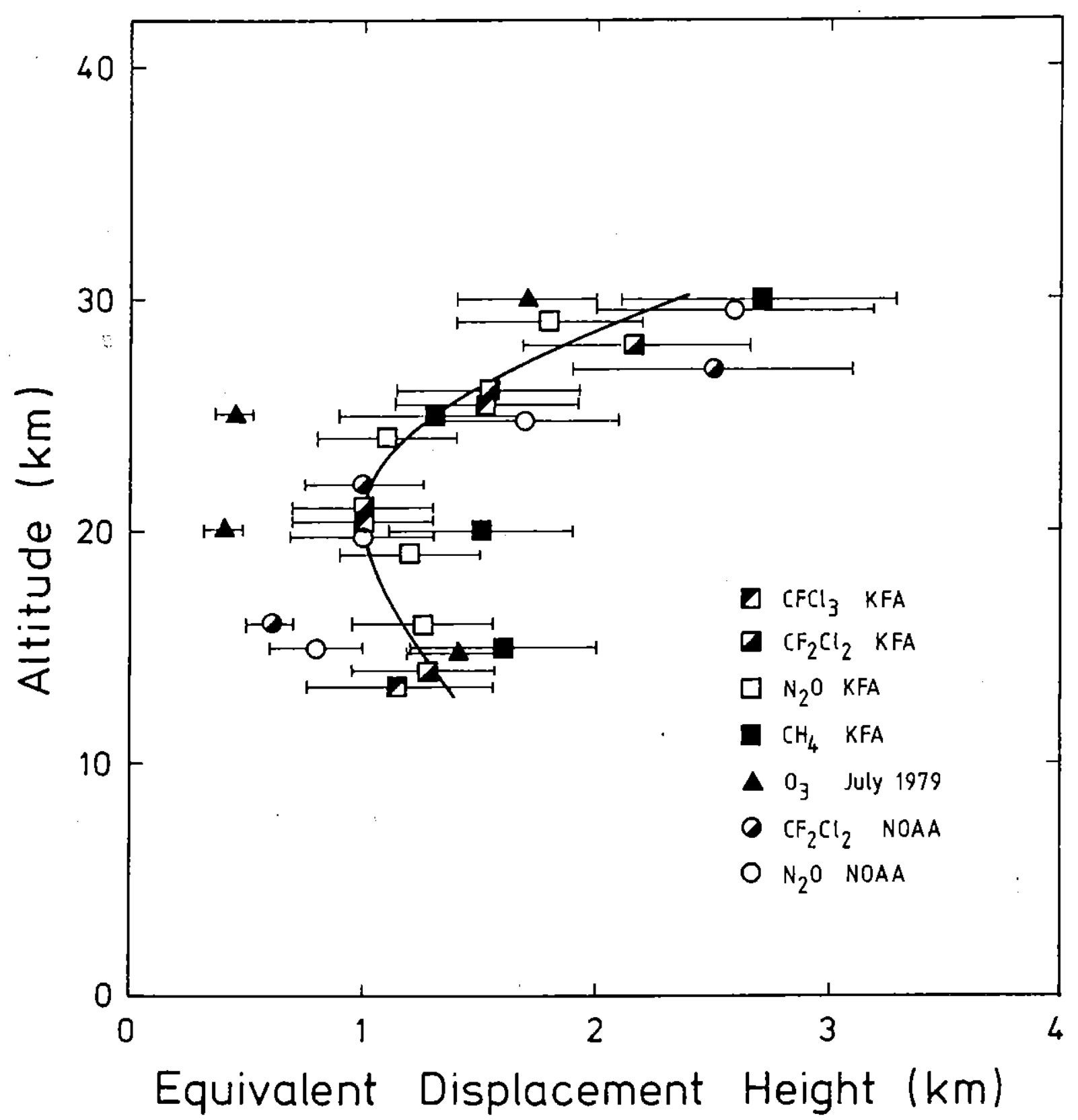

Figure 8 Superposition of the profiles of equivalent displacement height from Figures $3,4,6$. Only every 5 , point in altitude in each profile is shown, so that the data points are statistically independent (cf. text). For clarity, the altitudes are offset. 
Both transducers are calibrated before every second to third flight (A. Valette, 1982, private communication). On the other hand to mimic a mean displacement height of $3 \mathrm{~km}$ at $30 \mathrm{~km}$ altitude the pressure readings had to be off by ${ }_{-4}^{+9} \mathrm{mb}$, about a factor 10 above the stated uncertainty. Moreover, by implication the pressure measurements by 2 other groups had to be equally bad (Attmannspacher, 1980. 1981; Goldan et a1., 1980). This seems unlikely, since these authors claim even lower uncertainties in the pressure measurement than those given here. Thus we can also exclude errors in the measurement of ambient pressure as responsible for the observed similarity in the $\Delta$-profiles of $\mathrm{CH}_{4}, \mathrm{~N}_{2} \mathrm{O}, \mathrm{CF}_{2} \mathrm{Cl}_{2}$, $\mathrm{CFCl}_{3}$ and $\mathrm{O}_{3}$ and we conclude that most of variance observed in stratospheric mixing ratios of these trace gases is not experimental but due to natural causes.

This can be corroborated and even quantified to some extent. If there is a common cause for the variance in the stratospheric measurements, the individual deviations of the different species from the respective mean profiles should be correlated. For $\mathrm{CH}_{4}, \mathrm{~N}_{2} \mathrm{O}, \mathrm{CF}_{2} \mathrm{Cl}_{2}$, and $\mathrm{CFCl}_{3}$ this can be tested, because in our flights these gases were measured simultaneously; i.e. on the same samples. That correlation is indeed observed. As example, Figure 9 shows the correlation between the individual deviations from the mean for the $\mathrm{N}_{2} \mathrm{O}$ and $\mathrm{CH}_{4}$ data over Southern France. To be comparable the individual deviations are also expressed as vertical displacements. For $\mathrm{N}_{2} \mathrm{O}$ and $\mathrm{CH}_{4}$ the correlation is quite good. The corresponding correlation coefficient is shown in Table 1 which also summarizes the coefficients for the other trace gases. Also included is a correlation with the deviation from the mean temperature. The temperature used for that correlation is the average of the temperature measurements from radio sondes launched at or close to the dates of our balloon flights. There were no reliable measurements of ambient temperature aboard our balloons. The correlation coefficient between $O_{3}$ and $T$ was $0.45_{-0.6}^{+0,7}$ for the profiles in July 1979 and 10 to 


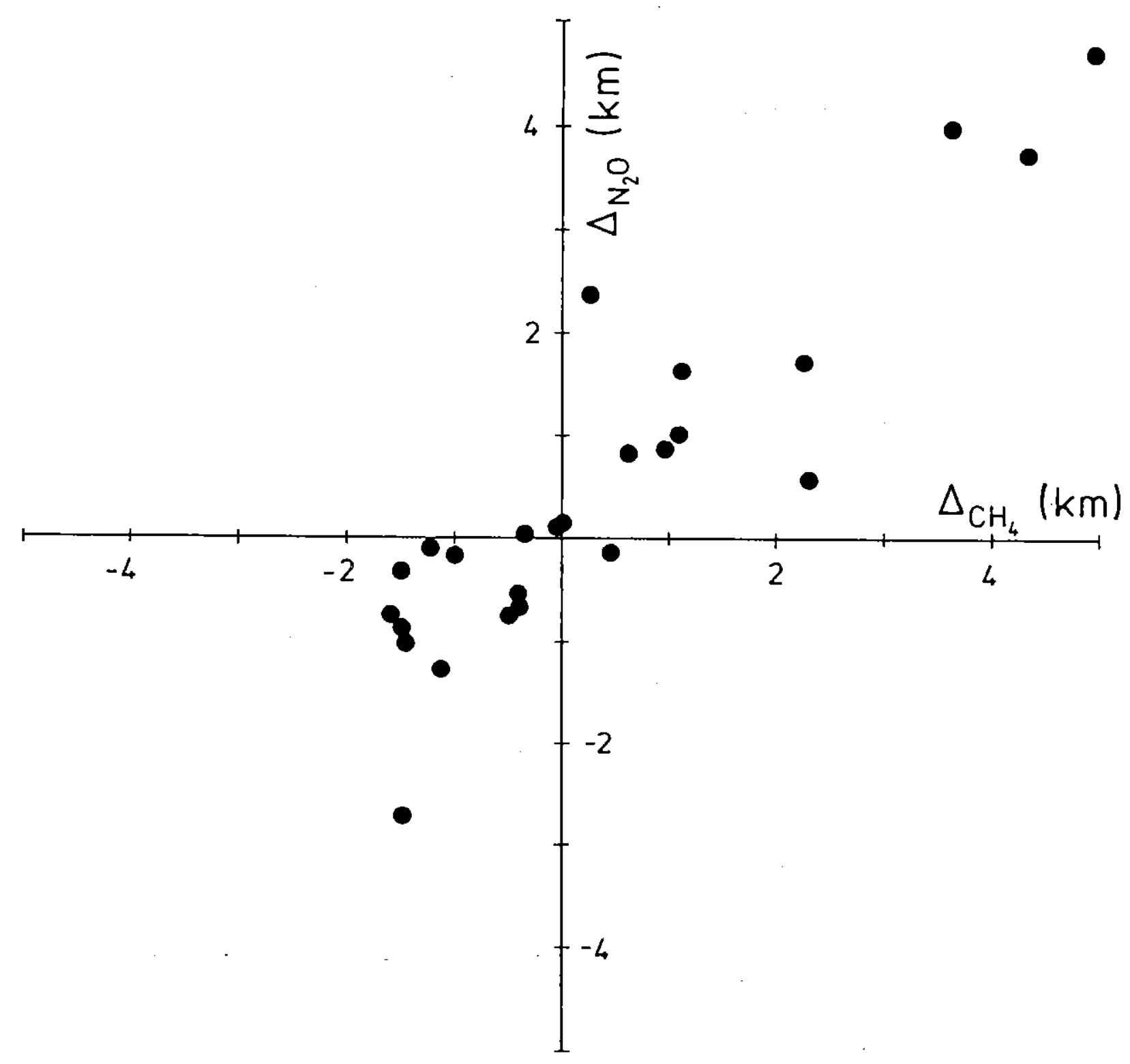

Figure 9 Correlation between the individual deviations from the mean for the $\mathrm{N}_{2} \mathrm{O}$ and $\mathrm{CH}_{4}$ measurements over Southern France above $15 \mathrm{~km}$ altitude. The deviations are expressed as vertical displacement. 
$30 \mathrm{~km}$ altitude. It should be noted that the correlation coefficients, $r$, presented in Table 1 are averages over the altitude range $15-35 \mathrm{~km}$. It is conceivable that $r$ might change somewhat with altitude. Indeed the data between 25 unto $35 \mathrm{~km}$ altitude give higher correlation coefficients - most likely because of the larger displacement heights encountered there.

From the correlation coefficients we can estimate what fraction of the observed variance, $\sigma^{2}$, was caused by a common mechanism. This fraction is given by $r^{2}$. From the correlation with $\mathrm{CH}_{4}$ the trace gas measured with the highest precision and the smallest variance we find that at least $81 \%$ of the variance in the stratospheric concentrations of $\mathrm{CH}_{4}$ and $\mathrm{N}_{2} \mathrm{O}, 62 \%$ of the variance of $\mathrm{CF}_{2} \mathrm{Cl}_{2}$ and $56 \%$ of the variance of $\mathrm{CFCl}_{3}$ are explained by that common mechanism. Like $r$, these upper limits represent averages over the altitude range from 15 to $35 \mathrm{~km}$.

The uncorrelated fraction of the variance, $1-r^{2}$, contains the instrumental uncertainties except that of the ambient pressure measurement. We can therefore use $1-r^{2}$ to derive an upper limit for the other instrumental uncertainties. This requires a few additional assumptions. When estimating the instrumental error of $\mathrm{CH}_{4}$ we assume that the unexplained fraction of the variance is caused to equal parts by the instrumental error in the $\mathrm{CH}_{4}$ and $\mathrm{N}_{2} \mathrm{O}$ measurement. This is certainly an overestimate of the $\mathrm{CH}_{4}$ error because the precision of our $\mathrm{CH}_{4}$ measurement is higher than that of $\mathrm{N}_{2} \mathrm{O}$ (and the other trace gases) and because there might be natural contributions to the non-correlated variance as well. When estimating the instrumental error of $\mathrm{N}_{2} \mathrm{O}, \mathrm{CF}_{2} \mathrm{Cl}_{2}$, and $\mathrm{CFCl}_{3}$ from the correlation with $\mathrm{CH}_{4}$, we assign all of the unexplained variance to the instrumental errors in the measurement of $\mathrm{N}_{2} \mathrm{O}, \mathrm{CF}_{2} \mathrm{Cl}_{2}$ and $\mathrm{CFCl}_{3}$, again an overestimate for the reasons just given. With these arguments the fraction 
Table 1: Correlation coefficients between the deviations of $\mathrm{CH}_{4}, \mathrm{~N}_{2} \mathrm{O}, \mathrm{CF}_{2} \mathrm{Cl}_{2}, \mathrm{CFCl}_{3}$ from the mean concentration profiles expressed as vertical displacement $(\mathrm{km})$, and between these and the temperature deviation, $\Delta T\left({ }^{\circ} \mathrm{K}\right)$. The errors indicate the $1 \sigma$ confidence range. The data are from our balloon flights over Southern France (Figure 1)

\begin{tabular}{|c|c|c|c|c|c|}
\hline & $\mathrm{CH}_{4}$ & $\mathrm{~N}_{2} \mathrm{O}$ & $\mathrm{CFCl}_{3}$ & $\mathrm{CF}_{2} \mathrm{Cl}_{2}$ & Temperature \\
\hline $\mathrm{CH}_{4}$ & - & $.90 \pm .04$ & $\begin{array}{r}.75+.08 \\
-.11\end{array}$ & $\begin{array}{r}.79+.07 \\
-.10\end{array}$ & $.64+.11$ \\
\hline $\mathrm{N}_{2} \mathrm{O}$ & $.90 \pm .04$ & - & $\begin{array}{r}.57+.12 \\
-.16\end{array}$ & $\begin{array}{r}.79+.07 \\
-.09\end{array}$ & $\begin{array}{r}.53+.14 \\
-.17\end{array}$ \\
\hline $\mathrm{CFCl}_{3}$ & $.75+.08$ & $\begin{array}{r}.57+.12 \\
-.16\end{array}$ & - & $\begin{array}{r}.67+.10 \\
-.13\end{array}$ & $\begin{array}{r}.35+.17 \\
-.20\end{array}$ \\
\hline $\mathrm{CF}_{2} \mathrm{Cl}_{2}$ & $\begin{array}{r}.79+.07 \\
-.10\end{array}$ & $\begin{array}{r}.79+.07 \\
-.09\end{array}$ & $.67+.10$ & - & $\begin{array}{r}.46+.15 \\
-.18\end{array}$ \\
\hline Temp. & $.64+.11$ & $\begin{array}{r}.53+.14 \\
-.17\end{array}$ & $\begin{array}{r}.35+.17 \\
-.20\end{array}$ & $.46+.15$ & - \\
\hline
\end{tabular}


$\sqrt{1-r^{2}}$ of the mean standard deviations shown in Figure 1 gives the upper limit of the instrumental uncertainties for $\mathrm{N}_{2} \mathrm{O}, \mathrm{CF}_{2} \mathrm{Cl}_{2}$ and $\mathrm{CFCl}_{3}$. For $\mathrm{CH}_{4}$ the fraction is $\sqrt{\left(1-r^{2}\right) / 2}$. Thus, at $20 \mathrm{~km}$, an altitude in the middle of the covered height range, for which the averaged correlation coefficients in table 1 should be reasonably representative, we obtain the following upper limits for the relative instrumental error: $\pm 1.6 \%$ for $\mathrm{CH}_{4} ; \pm 3.2 \%$ for $\mathrm{N}_{2} \mathrm{O} ; \pm 7.4 \%$ for $\mathrm{CF}_{2} \mathrm{Cl}_{2} ; \pm 14 \%$ for $\mathrm{CFCl}_{3}$. For $\mathrm{CH}_{2}, \mathrm{~N}_{2} \mathrm{O}$ and $\mathrm{CF}_{2} \mathrm{Cl}_{2}$ these estimates are close to the errors quoted by Volz et a1. (1981) and Fabian et a1. (1979) for the instrumental precision. For $\mathrm{CFCl}_{3}$ the upper limit is about 3 times higher than the quoted precision which may point to unidentified instrumental problems for that gas.

Altogether we conclude that the various experimental uncertainties contribute only a minor fraction to the observed variance in the stratospheric mixing ratios of the long lived trace gases. Thus the absolute values of the corresponding equivalent displacement heights, as well as the characteristic vertical profile of $\Delta$ in the stratosphere must be dominated by natural causes.

\section{Discussion}

\subsection{Theoretical expression for the equivalent displacement height}

In the previous chapter it was shown that experimental uncertainties contribute little to the variance observed in the stratospheric mixing ratios of $\mathrm{CH}_{4}, \mathrm{~N}_{2} \mathrm{O}$, $\mathrm{CF}_{2} \mathrm{Cl}_{2}$ and $\mathrm{CFCl}_{3}$. The observed variations in concentration must mainly be due to natural causes. Such natural variations can be generated by chemical reactions, by transport or by the action of both. In the case of transport it is the long range displacement by large scale eddies with typical time scales of a few days which is responsible for the fluctuations. Compared to this time 
scale the gases $\mathrm{CH}_{4}, \mathrm{~N}_{2} \mathrm{O}, \mathrm{CF}_{2} \mathrm{Cl}_{2}$ and $\mathrm{CFCl}_{3}$ are long lived. Below $30 \mathrm{~km}$ altitude $\mathrm{CH}_{4}, \mathrm{~N}_{2} \mathrm{O}, \mathrm{CF}_{2} \mathrm{Cl}_{2}$ have chemical lifetimes of longer than one year, $\mathrm{CFCl}_{3}$ of longer than one month. Hence these gases are quasi conservative in the considered altitude range, their chemistry does not contribute to the fluctuations. To a lesser approximation this holds also for $\mathrm{O}_{3}$ and the potential temperature, $\theta$. At $45^{\circ} \mathrm{N}$ the chemical lifetime of $\mathrm{O}_{3}$ becomes shorter than one month above $28 \mathrm{~km}$ altitude (NAS, 1975), and the temperature relaxes to its environmental value in about 10 days at all stratospheric altitudes due to Newtonian cooling (Dickinson, 1973). Although these times are still longer than the transport times we have to expect a certain dampening of the transport caused fluctuations due to chemical relaxation at the higher altitudes in the case of $0_{3}$, due to radiative relaxation at all altitudes in the case of $\theta$. In the following we consider all the trace gases as conservative, i.e. large scale transport is the only source of the observed fluctuations. Then, the momentary deviation from the local mean mixing ratio, $M^{\prime}=M-\bar{M}$, is in first approximation given by the Taylor expansion:

$$
M^{\prime}=\vec{T} \cdot \nabla \vec{M}
$$

where $\vec{l}$ is the displacement vector of the air parcel and $\nabla \vec{M}$ is the gradient of the mean mixing ratio (cf. Reed and German, 1965). This approximation corresponds to the mixing length hypothesis. It assumes that an air parcel started as an average sample of its environment and conserved its properties as it moved along a trajectory described by the vector $\overrightarrow{1}$ to the observation point. Figure 10 depicts the geometry in the 2 dimensions in which we will treat the problem. Equation (4) can be rewritten:

$$
M^{\prime}=|1| \cdot|\nabla \bar{M}| \cdot \cos \gamma
$$

where $\gamma$ is the angle between $\vec{i}$ and $\nabla \vec{M}$. 


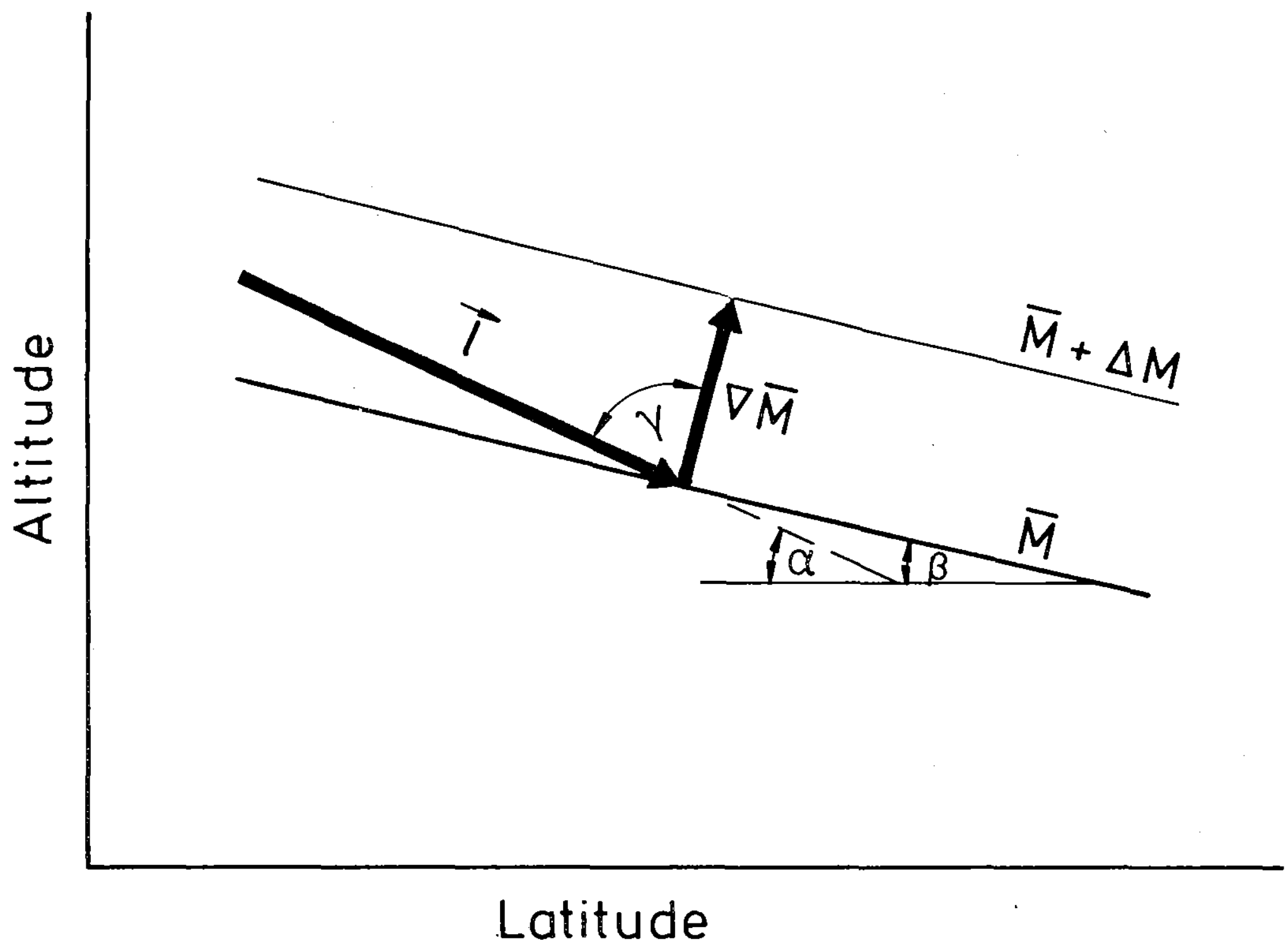

Figure 10 Geometry of mixing path, $\vec{l}$, and vertical gradient, $\nabla M$, used to derive a theoretical expression for the equivalent displacement height. 
Since the transport is quasi horizontal, and the angle of the momentary mixing surface, $\alpha$, and the mean angle of constant mixing ratio surface, $\bar{\beta}$, are very small (cf. Reed and German, 1965), the angle $\gamma$ is close to $90^{\circ}$ and in good approximation

$$
\cos \gamma=\alpha-\bar{\beta}
$$

For the same reason the horizontal component of $\nabla \bar{M}$ is small and thus

$$
\overline{\nabla M} \cong \frac{\partial M}{\partial z}
$$

Inserting (6), and (7) in (5) we obtain

$$
M^{1}=|1| \cdot\left|\frac{\partial \bar{M}}{\partial z}\right|(\alpha-\bar{\beta})
$$

The local temporal variance $\sigma_{j}^{2}$ of the mixing ratio for the gas $j$ is then given by the time average

$$
\sigma_{j}^{2}=\overline{M_{j}^{2}}=1^{2}\left(\frac{\bar{M}_{j}}{\partial z}\right)^{2}\left(\bar{\beta}_{j}^{2}+\alpha^{2}-2 \alpha \bar{\beta}_{j}\right)
$$

where the time averaging is denoted by the bar.

Like Reed and German (1965) we assume that the mixing length, $|1|$ and the slope of the mixing path, $\alpha$, are not correlated. Equation (9) can then be simplified to

$$
\sigma_{j}^{2}=\overline{1}^{2} \cdot\left(\frac{\bar{M}_{j}}{\partial z}\right)^{2}\left[\left(\bar{\beta}_{j}-\bar{\alpha}^{2}+\overline{\alpha^{2}}\right]\right.
$$


where $\alpha^{\prime}$ is the deviation from the mean slope, $\alpha^{\prime}=\alpha-\bar{\alpha}$, and $\alpha^{2}$ is the variance of the slope of the mixing surface. Finally, inserting eq. (2), we obtain the desired expression for the equivalent displacement height.

$$
\Delta_{j}^{2}=\overline{1}^{2} \cdot\left[\left(\bar{\beta}_{j}-\bar{\alpha}^{2}+\bar{\alpha}^{2}\right]\right.
$$

Apart from the slope of the surface of constant mixing ratio, $\beta_{j}, \Delta_{j}$ depends only on parameters describing the common transport. For the longlived trace gases the individual $\beta_{j}$ are expected to differ only slightly. Consequently eq. (11) predicts similar values for the respective equivalent displacement heights, as has been observed (cf. Figure 8 ).

There is another approach to derive a theoretical expression for the equivalent displacement height. Since it does provide additional insight in the transport processes responsible for the variances, it will briefly be discussed here too. It is based on the work of Matsuno (1980) who investigated the air parcel trajectories caused by planetary waves. Projected onto the meridional plane these trajectories take the form of a slanted ellipse. In particular Matsuno (1980) considered the problem where a locally deviating mixing ratio relaxes to the zonal mean with a characteristic time, $\tau$. This time, $\tau$, takes into account, both, dissipation by small scale diffusion and photochemical relaxation. Combining the trajectory of an air parcel swept around the globe in a planetary wave with concurrent adjustment of the mixing ratio in this air parcel to the new environment with the relaxation time $\tau$, he was able to derive an expression for the deviation of the local mixing from the zonal mean at a given latitude and aititude (his equation 4.6). This expression can be used instead of our equation (8) to define the local deviation, $M^{\prime}$. In our terminology it reads: 


$$
\begin{aligned}
M^{\prime}(\varphi)=-1_{y} \cdot \frac{\partial M}{\partial z}\left(\phi_{1} \cos \varphi+\phi_{2} \sin \varphi\right)-a_{z} \cdot \frac{\partial M}{\partial z}\left(-\phi_{2} \cos \varphi+\phi_{1} \sin \varphi\right)+ \\
\quad I_{z} \frac{\partial M}{\partial z}\left(\phi_{1} \cos \varphi+\phi_{2} \sin \varphi\right)
\end{aligned}
$$

Here $l_{y}$ and $l_{z}$ are the $y$ - and $z$ - components of the displacement vector $\overrightarrow{1} ; a_{z}$ corresponds to the minor (vertical) axis of the ellipse; $\varphi$ describes the longitude, and

$$
\begin{aligned}
& \phi_{1}=\frac{\omega \tau}{1+\omega^{2} \tau^{2}} \\
& \phi_{2}=\frac{\omega^{2} \tau^{2}}{1+\omega^{2} \tau^{2}}
\end{aligned}
$$

where $\tau$ is the relaxation time defined above and $\omega$ is the intrinsic frequency of the planetary wave. Matsuno (1980) used the example of a planetary wave number 1 in a westerly flow of $30 \mathrm{~m} \mathrm{sec}^{-1}$ at $60^{\circ}$ latitude. The resulting $\omega=10^{-5}$ $\sec ^{-1}$ will also be adopted below.

Forming $M_{2}^{\prime 2}(\varphi)$, integrating over $\varphi$ and noting that $\frac{\partial M}{\partial y} / \frac{\partial M}{\partial z}=\bar{\beta} ; \frac{1_{z}}{1_{y}}=\bar{\alpha}$ and replacing $1_{y}^{2} \approx 1^{2} ;\left(\frac{T_{y}}{T_{y}}\right)^{2}=\overline{\alpha^{\prime 2}}$ we obtain for the equivalent displacement height:

$$
\Delta^{2}=\frac{1}{2}^{2}[\overline{(\alpha-\beta}-\bar{\beta})^{2}+\overline{\alpha^{\prime 2}}\left(\phi_{1}^{2}+\phi_{2}^{2}\right)
$$

in close analogy to expression (11). Eq. (11a) presents a zonal average for $\Delta^{2}$. Owing to phase shifts in the planetary waves, it should be equivalent to the temporal average given by eq. (11).

Because Matsuno (1980) treated elliptical polarized waves whereas the present approach using the mixing length hypothesis recognizes only linearly polarized waves, the meaning of the symbols has changed slightly; $\vec{\alpha}$ is now the inclina- 
tion of the main axis of the ellipse; $\overline{\alpha^{2}}$ corresponds to the square of the ratio of minor to major axis (cf. Danielsen, 1981). Moreover there is now a factor, $\left(\phi_{1}^{2}+\phi_{2}^{2}\right)$ which accounts for relaxation or damping. However the latter modification does not change much the numerical value of $\Delta$. For the trace substances considered here, for nearly all of which relaxation is dominated by mixing, $\tau$ is on the order to 10 days (Mahlmann, private communication). With that and an intrinsic frequency $\omega$ of $10^{-5}\left(\phi_{1}^{2}+\phi_{2}^{2}\right)$ is very close to unity. Such that apart from the factor of $1 / 2$ which seems to come mainly from the reinterpretation of 1 , as length of the main axis of the ellipse, $1 y$, corrections appear minor. The simple approach of the mixing length and the more sophisticated approach based on Matsuno's (1980) formulation lead to nearly identical results for the trace substances considered here. The latter approach, however, is more instructive. It presents a strong indication that the quasi horizontal transport responsible for the observed variance may well be due to planetary waves - at least in the lower stratosphere. It presents a more precise interpretation of the transport parameters $\bar{\alpha}, \overline{\alpha^{\prime 2}}$ and $1^{2}$ in terms of elliptically polarized waves. And it allows to calculate the dampening influence of small scale mixing and chemical relaxation on the variance and equivalent displacement height in a quantitative way. (For the trace substances considered here dampening apperas sma 11.)

Nevertheless, since it contains fewer parameters, expression (11) based on the simple mixing lengths hypothesis will be preferred in the calculations of the equivalent displacement height following below.

\subsection{Calculation of the transport parameters}

To calculate the equivalent displacement height, $\Delta_{i}$, information on the transport parameters $1^{2}, \bar{\alpha}$ and $\overline{\alpha^{\prime 2}}$ is required. In addition the mean meridional slope of the surface of constant mixing ratio, $\bar{\beta}_{j}$ has to be known. On the other hand 
eq. (11) can be used to derive the transport parameters, i.e. mixing length $\sqrt{\gamma^{2}}$, mean meridional slope of the mixing surface, $\bar{\alpha}$, and the variance of this slope, $\overline{\alpha^{\prime 2}}$, provided $\bar{\beta}_{i}$ and $\Delta_{i}$ are known for at least three trace gases or other independent conservative quantities like the potential temperature. Denoting those 3 trace quantities by the indices $1,2,3$ we obtain the following expressions:

$$
\begin{aligned}
& \vec{\alpha}=\frac{1}{2} \cdot \frac{\left(\bar{\beta}_{2}^{2} \cdot \frac{\Delta_{1}^{2}}{\Delta_{2}^{2}}-\overline{\beta_{1}^{2}}\right) \cdot\left(1-\frac{\Delta_{1}^{2}}{\Delta_{3}^{2}}\right)-\left(\bar{\beta}_{3}^{2} \frac{\Delta_{1}^{2}}{\Delta_{3}^{2}}-\overline{\beta_{1}^{2}}\right)\left(1-\frac{\Delta_{1}^{2}}{\Delta_{2}^{2}}\right)}{\left(\bar{\beta}_{2} \cdot \frac{\Delta_{1}^{2}}{\Delta_{2}^{2}}-\overline{\beta_{1}}\right) \cdot\left(1-\frac{\Delta_{1}^{2}}{\Delta_{3}^{2}}\right)-\left(\bar{\beta}_{3} \frac{\Delta_{1}^{2}}{\Delta_{3}^{2}}-\overline{\beta_{1}}\right)\left(1-\frac{\Delta_{1}^{2}}{\Delta_{2}^{2}}\right)} \\
& \overline{\alpha^{\prime 2}}=\frac{\frac{\Delta_{1}^{2}}{\Delta_{2}^{2}}\left(\vec{\beta}_{2}-\bar{\alpha}^{2}-\left(\vec{\beta}_{1}-\bar{\alpha}^{2}\right.\right.}{1-\frac{\Delta_{1}^{2}}{\Delta_{2}^{2}}} \\
& \overline{1^{2}}=\frac{\Delta_{i}^{2}}{\left(\overline{\beta_{i}}-\bar{\alpha}\right)^{2}+\overline{\alpha^{\prime 2}}}
\end{aligned}
$$

For a few trace quantities 2-dimensional meridional fields are available from which the required $\beta_{i}$ can be estimated. These are: the potential temperature which is derived from the temperature and pressure data listed in the Air Force Reference Atmospheres (Cole and Kantor, 1978), the $0_{3}$ mixing ratio (Dütsch, 1978 ) and the $\mathrm{CH}_{4}$ mixing ratio for which a crude $2 \mathrm{D}$ field is obtained from the present measurements at $43^{\circ} \mathrm{N}$ and the measurements by NCAR at $32^{\circ} \mathrm{N}$ and $52^{\circ} \mathrm{N}$ (cf. Ehhalt, 1980). The meridional fields of $\theta, \mathrm{O}_{3}$ and $\mathrm{CH}_{4}$ for the Northern Hemisphere are shown in Figure 11. They all refer to the month of June, or the summer months in the case of $\mathrm{CH}_{4}$. We note that the patterns of the isopleths differ substantially. Whereas the meridional slope of the isentropes is gentle everywhere and decreases with increasing altitude, the corresponding slope for $\mathrm{CH}_{4}$ is steeper and increases with altitude; in the case of $\mathrm{O}_{3}$ we even observe a change in the sign of the slope as we go to higher altitudes. We also note that the data base from which the $2 \mathrm{D}$ fields were derived is different than that from which the $\Delta$ profiles were derived which leads to sight incom- 


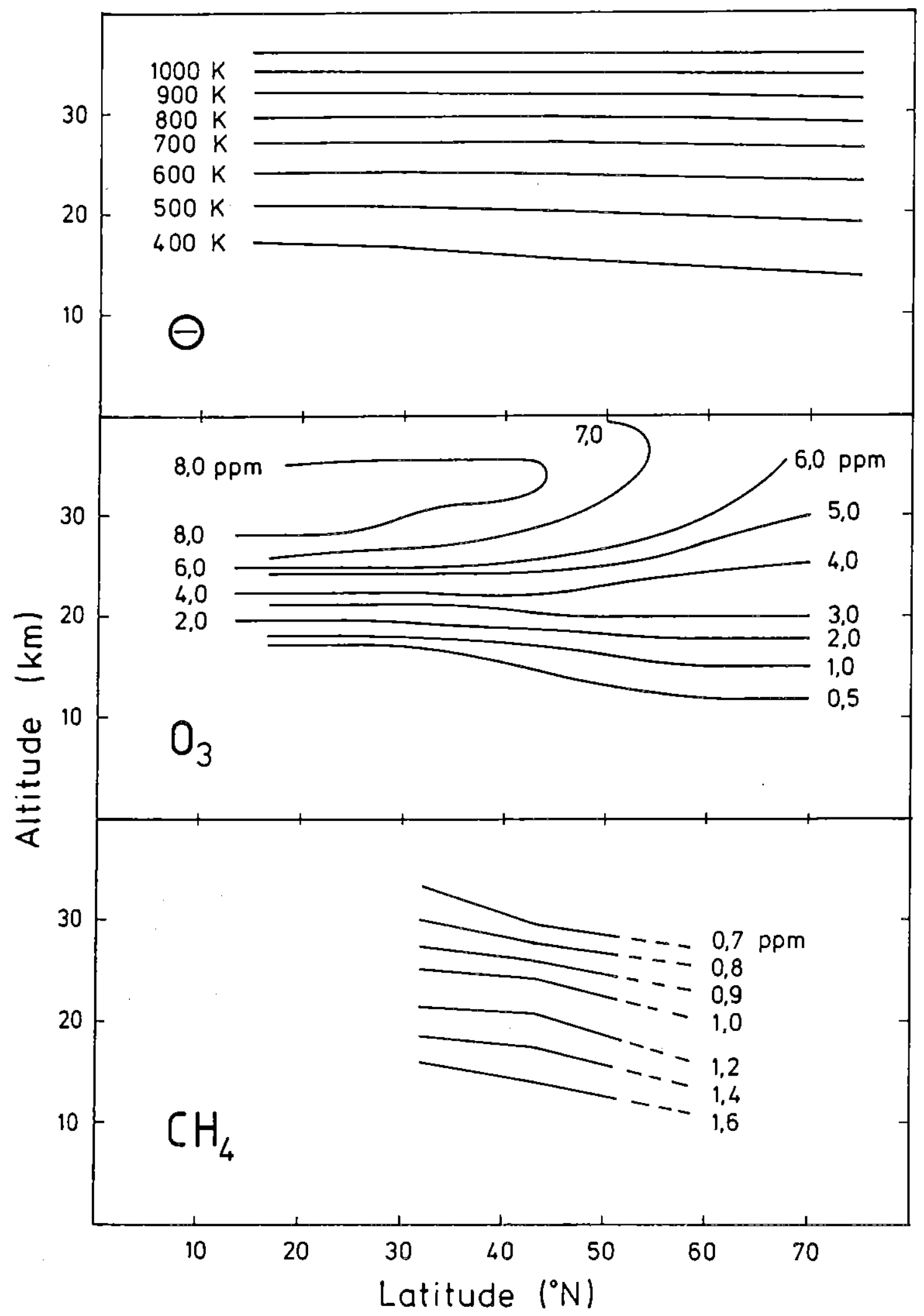

Figure 11 2-dimensional fields of the potential temperature, $\theta$, and the mixing ratios of $\mathrm{O}_{3}$ and $\mathrm{CH}_{4}$ during June. They are based on the data given by Cole and Cantor (1978), Duitsch (1978) and Ehhalt (1980). 
patibilities. For example the mean vertical $0_{3}$ profile at $48^{\circ} \mathrm{N}$ latitude shown in Figure 5 shows slight deviations from the one prescribed by the contours in Figure 11 .

The angles of constant mixing ratio, $\beta_{j}$, at $43^{\circ} \mathrm{N}$ latitude extracted from the $2 \mathrm{D}$ fields are shown in Figure 12. They reflect what has been said above: $\beta_{\theta}$ increases monotonically from $-8 \times 10^{-3}(\mathrm{~km} / \mathrm{km})$ at $14 \mathrm{~km}$ altitude to virtually zero at $32 \mathrm{~km} ; \mathrm{B}_{\mathrm{CH}_{4}}$ increases from value of $-1.7 \times 10^{-3}$ at $14 \mathrm{~km}$ to a maximum of $-1.2 \times 10^{-3}$ around $24 \mathrm{~km}$ altitude above which it decreases rapidly to reach $-2.5 \times 10^{-3}$ at $30 \mathrm{~km} ; \mathrm{B}_{3}$ increases monotonically from $-1.3 \times 10^{-3}$ at $14 \mathrm{~km}$ to $+2.5 \times 10^{-3}$ at $30 \mathrm{~km}$ crossing the zero line around $22 \mathrm{~km}$ altitude. With these values for $\beta_{i}$ and the $\Delta_{i}$ from Figures $3,6,7$ we attempted to solve eq. (12). The values of $\bar{\alpha}$ thus obtained were quite reasonable and close to those shown in Figure 13. However when we proceeded to solve eq. (13) for $\overline{\alpha^{\prime^{2}}}$ we obtained small but negative values at nearly all altitudes. This is physicaliv not possible, the smallest value that $\overline{\alpha^{\prime 2}}$ can assume is zero. These negative values are probably a result of the slight incompatibilities or uncertainties in the $\Delta_{j}$ and $\beta_{j}$ profiles. We therefore tried a more modest approach and assumed $\overline{\alpha^{12}}$ to be zero. The justification for that will be discussed below. This assumption entered into eq. (11) led to following solutions for $\bar{\alpha}$ :

$$
\bar{\alpha}_{i j}=\frac{\bar{\beta}_{i} \Delta_{j} \pm \bar{\beta}_{j} \Delta_{i}}{\Delta_{j} \pm \Delta_{i}}
$$

The solutions (15) require the knowledge of $\Delta_{i}$ and $\bar{\beta}_{i}$ from two trace quantities only. They have a simple geometric interpretation. The "positive" solution for $\bar{\alpha}_{i j}$ represents an average of the two $\bar{\beta}_{i}$ values weighted by the $\Delta_{i}$ values in such a way that $\bar{\alpha}_{i j}$ falls between the two $\bar{\beta}_{i}$ values and closer to that with the lower $\Delta$ value. The "negative" solution provides an $\bar{\alpha}_{i j}$ value which lies outside the interval defined by the two $\beta_{i}$ values: namely on the outer side of that $\bar{\beta}_{j}$ with the lower $\Delta_{i}$ value. If the two $\Delta_{i}$ values are about equal the 


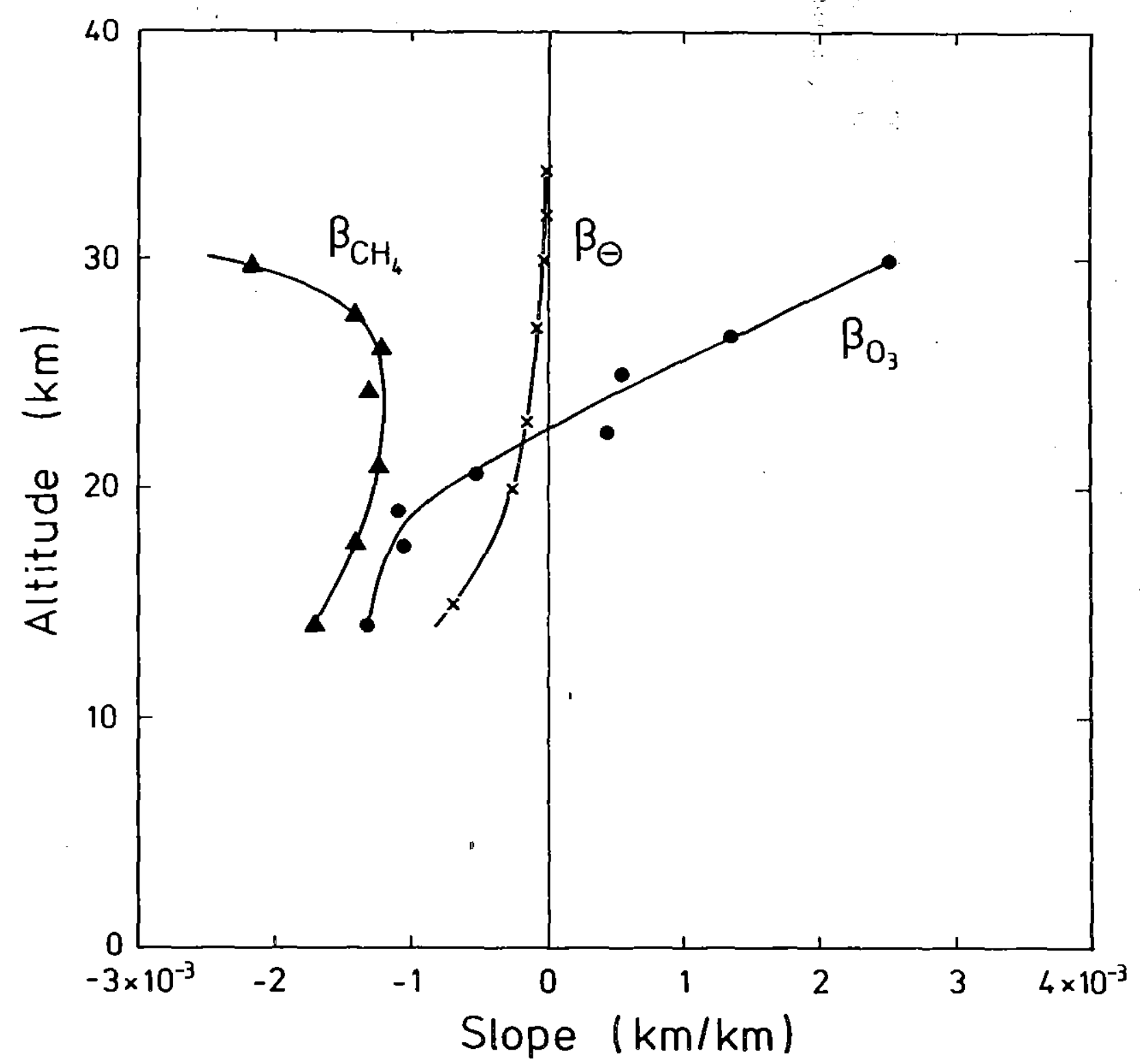

Figure 12 Mean meridional slope of the surfaces of constant potential temperature, $\beta_{\theta}$, and of constant mixing ratio of $\mathrm{O}_{3}, \bar{B}_{0_{3}}$, and $\mathrm{CH}_{4}, \bar{B}_{\mathrm{CH}_{4}}$, at $43^{\circ} \mathrm{N}$, as derived from Figure 11 . 
error in the negative solution for $\bar{\alpha}_{i j}$ can become large. Having information on three trace quantities provides some redundancy with three pairs of solutions for $\bar{\alpha}_{i j}$. The values for $\bar{\alpha}_{i j}$ calculated from eq (15) show some scatter because of uncertainties in the values for $\bar{\beta}_{i}$ and $\Delta_{i}$ and some judgement has to be exercised to select the proper 3 solutions, $\overline{\alpha_{i j}}$, that are eventually averaged to obtain a mean value for the mean meridional slope of the mixing surface, $\bar{\alpha}$. The selection was guided by the solution of eq. (12) which gave a unique value of $\bar{\alpha}$.

The resulting $\bar{\alpha}$ are shown in Figure 13 as function of the altitude. They apply for June and $43^{\circ} \mathrm{N}$ latitude. As expected from the small equivalent displacement heights for the potential temperature, $\Delta_{\theta}$, the mean slope of the mixing surface, $\bar{\alpha}$, is relatively close to the slope of the isentropic surface, $\beta_{\theta}$ (cf. Figure 12). But the angle $\bar{\alpha}$ increases more strongly with altitude than $\beta_{\theta}$ and assumes positive values above about $25 \mathrm{~km}$ altitude. This is a consequence of the steep positive slope of the $0_{3}$ isopleths at these altitudes. The scatter among the $\overline{\alpha_{i j}}$ in these altitudes is relatively large. The spread of the 3 values for $\overline{\alpha_{i j}}$ is indicated by the error bars of $\bar{\alpha}$.

Figure 13 indicates that at lower stratospheric altitudes up to $22 \mathrm{~km}$ altitude transport takes place along surfaces.sloping downward towards the pole slightly more steeply than the isentropes, a fact which is generally accepted. However, above $25 \mathrm{~km}$ the angle $\bar{\alpha}$ obtained here for June and $43^{\circ} \mathrm{N}$ suggests transport surfaces sloping upward towards the pole. The uncertainty in that statement is probably large, and depends strongly on the knowledge of the correct mean slope of the $\mathrm{O}_{3}$ isopleths, $\overline{\mathrm{B}}_{\mathrm{O}_{3}}$.

The $\bar{\alpha}$ derived here can be compared with values calculated by Reed and German, 1965, from heat flux considerations. Their values for $40^{\circ} \mathrm{N}$ and the period July 


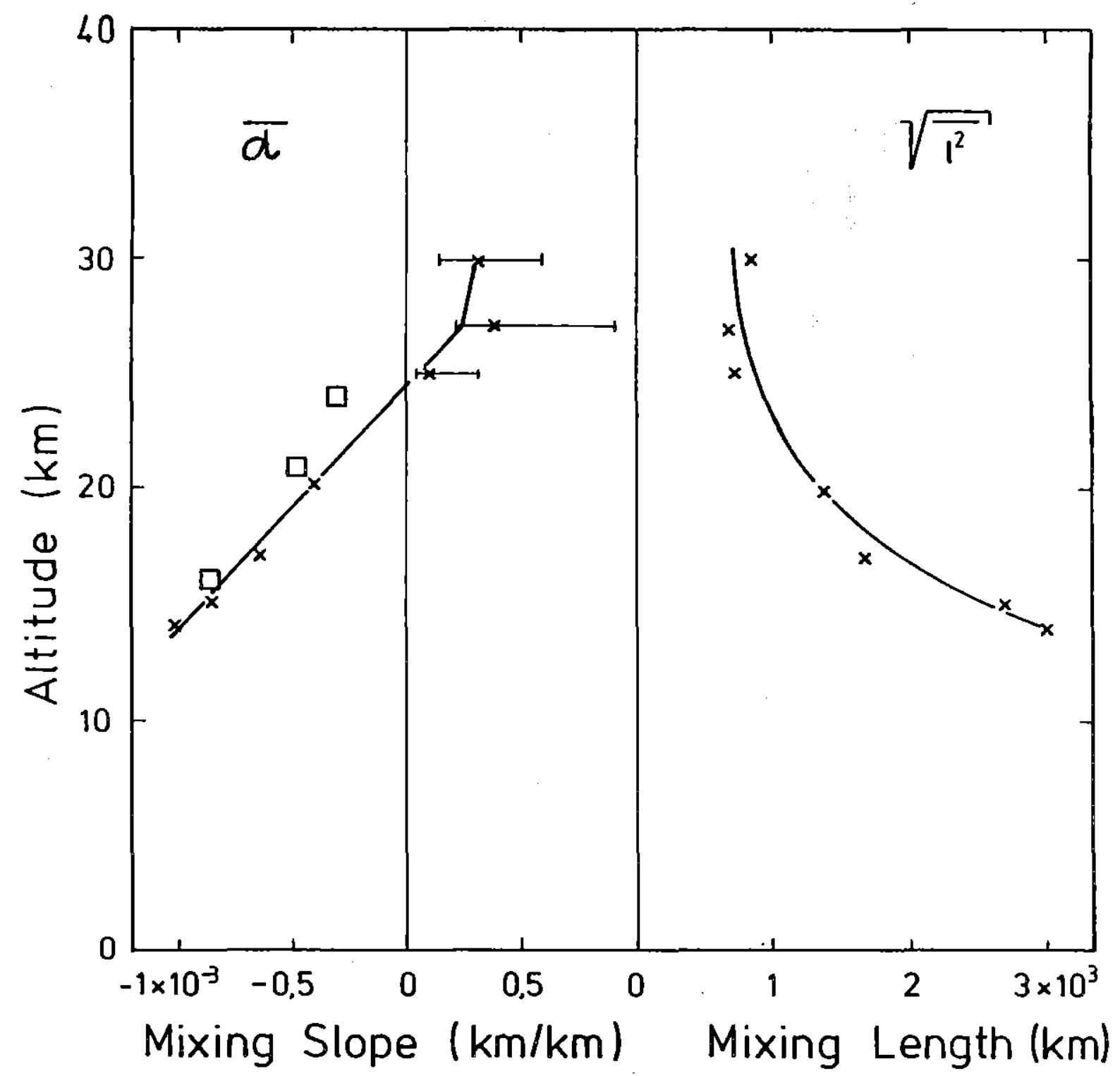

Figure 13 Values of the mean meridional slope of mixing surface, $\bar{\alpha}$, and mixing length, $\sqrt{1^{2}}$, as derived from eq. (15), eq. (14) and the empirical values for $\bar{B}$ and $\Delta$. The data apply for $32^{\circ} \mathrm{N}$ and June. The open squares are the $\bar{\alpha}$ given by Reed and German (1965) for July to September at $40^{\circ} \mathrm{N}$ latitude. The curves are hand drawn to match the data. 
to September are included in Figure 13. They are restricted to the lower stratosphere but also indicate an increase in $\bar{\alpha}$ with altitude, though slightly weaker than the one found here.

With $\bar{\alpha}$ from Figure 13 and assuming $\overline{\alpha^{\prime 2}}=0$ the mixing length, $\sqrt{1^{2}}$ can be calculated from eq. (14). The solutions for the different pairs of trace quantities differ sometimes substantially. The average $\sqrt{1^{2}}$ is also presented in Figure 13 . It decreases with altitude from about $3000 \mathrm{~km}$ at $14 \mathrm{~km}$ to about $800 \mathrm{~km}$ at $25 \mathrm{~km}$ altitude. Between 25 and $30 \mathrm{~km}$ altitude $\sqrt{1^{2}}$ remains virtually constant. It is noted that the relatively small values of the mixing lengths at high altitudes are quite helpful for the present approach, otherwise because of the strong curvature in the $\mathrm{O}_{3}$ isopleths the first order approximation utilized here (cf. eq. (5)) would become poor.

Although the variance of the slope of the mixing surface $\overline{\alpha^{\prime 2}}$, cannot be calculated, an upper limit for it can be estimated from eq. (11) assuming $(\bar{\alpha}-\bar{\beta})=0$. If this is done for $\Delta_{\theta}^{2}$, which has the smallest values and thus provides the lowest upper limit, we obtain

$$
\overline{\alpha^{\prime 2}} \leqq \frac{\Delta_{\theta}^{2}}{\overline{1^{2}}}
$$

Since $\Delta_{\theta}$ is smaller than $\Delta_{\mathrm{CH}_{4}}$ and $\Delta_{0_{3}}$ by a factor of at least 3 at the lower, by a factor of at least 10 at the higher altitudes, it follows that the contribution of $\overrightarrow{\alpha^{\prime 2}}$ to the observed $\Delta_{0_{3}}^{2}$ and $\Delta_{\mathrm{CH}_{4}}^{2}$ must be small indeed at all altitudes. At about $24 \mathrm{~km} \vec{\alpha}=\beta_{\theta}$ (cf. Figures 12 and 13). At that altitude $\overline{\alpha^{\prime 2}}=$ $\frac{\Delta_{\theta}^{2}}{\overline{j^{2}}}$. Inserting the values for $\Delta_{\theta}$ and $\overline{1^{2}}$ (from Figures 7 and 13 ) we obtain $\overline{\alpha^{2}}=$ $1.1 \times 10^{-8}$. Strictly speaking this is stil1 an upper limit, because we are neglecting the contributions by experimental errors to $\Delta_{\theta}$. 
Yet $\overline{\alpha^{\prime 2}}$ is probably different from zero, and the $\bar{\alpha}_{i j}$ derived by eq. (15) have to be modified. However that modification is small for the following reason. We could include the contribution of $\overline{\alpha^{\prime 2}}$ to the observed $\Delta_{j}$ value by writing $\Delta_{i}{ }^{2}=$ $\Delta_{i}^{2}-\overline{1^{2}} \cdot \overline{\alpha^{\prime}}$ (cf. eq. (11)), and inserting it into eq. (15). Since $\Delta_{i}{ }^{2}$ is smaller than $\Delta_{j}^{2}$, all this does, is to pull the solutions for $\vec{\alpha}_{i j}$ even closer to the $\bar{\beta}_{j}$ with the lowest $\Delta_{i}$ value. Since $\Delta_{\theta}$ is already so much smaller than ${ }^{\Delta} \mathrm{CH}_{4}$ or $\Delta_{\mathrm{O}_{3}}$, and thus $\bar{\alpha}_{i j}$ close to $\bar{\beta}_{\theta}$ the expected corrections to the $\bar{\alpha}_{i j} \mathrm{cal}$ culated via eq. (15) are small, certainly much smaller than the other uncertainties already mentioned. We therefore can safely neglect $\overline{\alpha^{\prime 2}}$ in the evaluation of the mean slope of the mixing surfaces, $\bar{\alpha}$. A nonzero variance of the mixing slope, $\overline{\alpha^{\prime 2}}$, will, however, change the calculated mixing length, $\sqrt{1^{2}}$ (cf. eq. (14)), particularly that calculated from $\Delta_{\theta}$.

As a final check theoretical curves of $\Delta_{i}$ are calculated from eq. (11) and the transport parameters presented in Figure 13 and $\bar{\beta}_{j}$ in Figure $12 . \overline{\alpha^{\prime 2}}$ is assumed to be zero. They are compared with the observed values of the equivalent displacement height in Figure 14. For clarity the observed $\Delta$ values from Figures 3 , 6,7 are shown only every two to three kilometers. The agreement is quite reasonable. Not only is the shape of the observed $\Delta$-profiles well reproduced, but also the absolute values. This is all the more gratifying since $\Delta_{\theta}$ is about an order of magnitude smaller than $\Delta_{\mathrm{CH}_{4}}$ and $\Delta_{0_{3}}$. Despite the fact that the sources and thus the $2 \mathrm{D}$ meridional concentration fields of $\theta, \mathrm{O}_{3}$ and $\mathrm{CH}_{4}$ are quite different, the variances of the three trace quantities are well explained by the same transport parameters $\bar{\alpha}$ and $\overline{1^{2}}$. Obviously the agreement between the calculated and the empirical $\Delta$ profiles would improve significantly, if we allowed $\overline{\alpha^{\prime 2}}>0$. For example using the value derived above $\overline{\alpha^{12}}=1.1 . \times 10^{-8}$, and assuming it to be constant with altitude, would remove the zero value for $\Delta$ at $22 \mathrm{~km}$ altitude and the rather angular approach towards it from the profiles of $\Delta_{\theta}$ and $\Delta_{0_{3}}$. Correcting also for the concurrent change in $\overline{l^{2}}$ would give quite good 


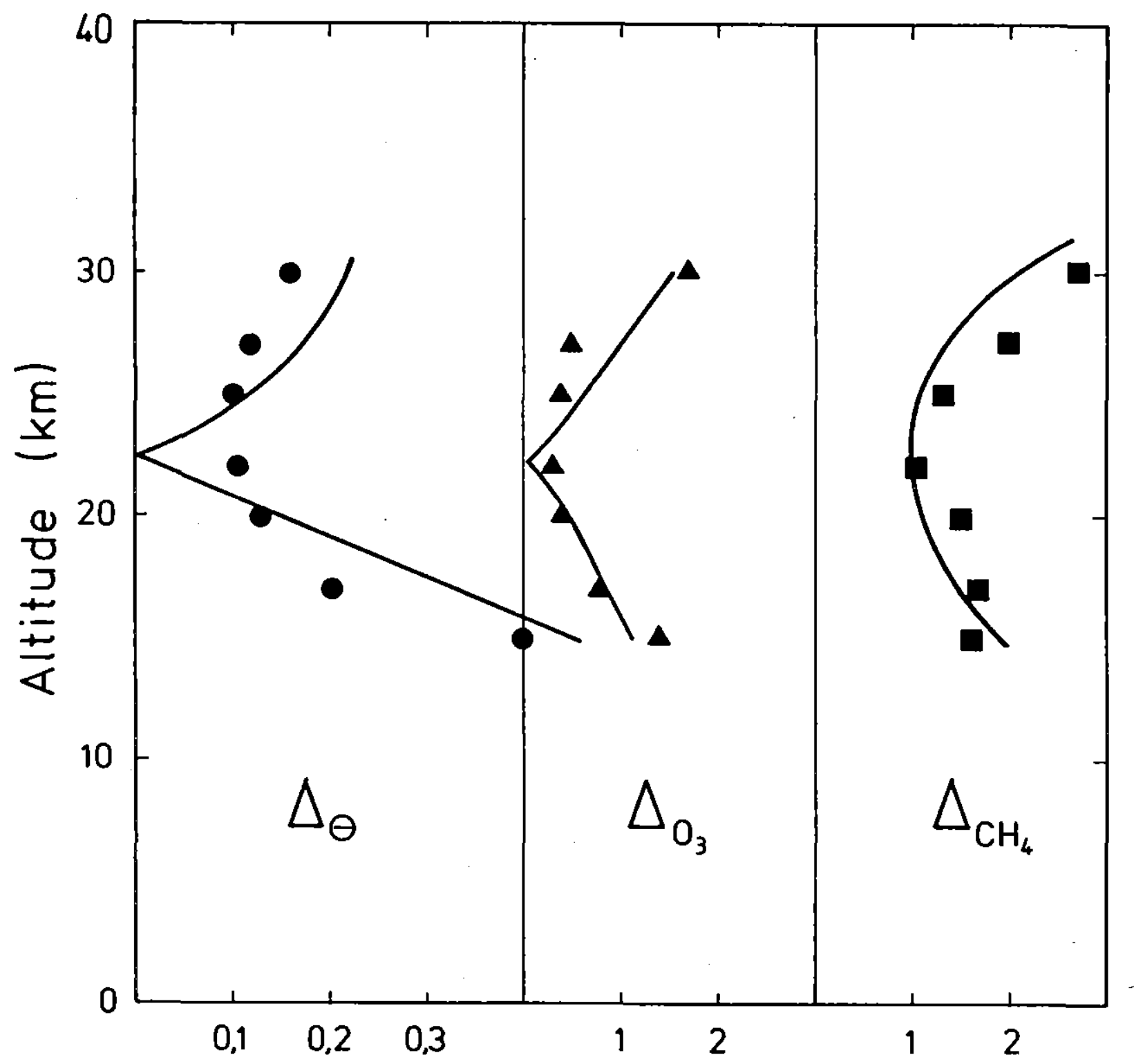

Equivalent Displacement Height $(\mathrm{km})$

Figure 14 Comparison of the displacement heights calculated from eq. (11) and the empirical values from Figures 3, 5, and 8. For clarity not ail data points are shown. 
agreement for $\Delta_{\theta}$. We might take this as a strong indication that $\overline{\alpha^{2}}>0$. Since we do not know the actual profile of $\overline{\alpha^{\prime 2}}$, we refrain from this correction at present. Even without correction for $\overline{\alpha^{\prime^{2}}}>0$ the simple model of the mixing length in the meridional plane seems to explain the main features of all observed equivalent displacement heights, $\Delta_{j}$. This lends also more credence to our contention that the variances are produced by transport and can thus be used to derive information about it. It further shows that despite their inherent shortcomings the profiles of $\Delta_{j}$ and $\bar{\beta}_{j}$ utilized here are not too far from actuality.

The good agreement appears also to leave little room for additional contributions to the variance including those by zonal transport. Thus we conclude that the mean zonal gradients in the mixing ratios of longlived trace gases must be small, and that a mean concentration profile measured at a single longitude is reasonably representative of the zonal average. This observation is also corroborated by the good agreement in the mean concentration profiles of $\mathrm{N}_{2} \mathrm{O}$, $\mathrm{CF}_{2} \mathrm{Cl}_{2}$ and $\mathrm{CFCl}_{3}$ over Laramie (Goldan et a1., 1980) and Southern France (Fabian et al., 1979, Ehhalt, 1980).

\section{Conclusion}

Finally we return to the question which started this investigation: What are the uncertainties which should be assigned to the average measured trace gas profile? It has been demonstrated above that in the case of careful measurements most of the observed variance for the long lived trace gases is caused by transport. In that case the main source of the uncertainty has been identified. Moreover the frequency distribution of the deviations from the mean is reasonably narrow (see figure 1) and allows an estimate of the mean standard deviation $\sigma$. Thus the uncertainty of the respective mean profile is given by the standard deviation of the mean: $\sigma / \sqrt{n_{j}}$, where $n_{j}$ is the number of data points in the height interval considered. 
The uncertainties in the mean profiles of longlived trace gases are thus a factor 3 to 4 smaller than the error bars given in Figure 1 which indicate $\sigma$. Consequently the uncertainty is $2 \%$ or less for $\mathrm{CH}_{4}, \mathrm{~N}_{2} \mathrm{O}$ and $\mathrm{CF}_{2} \mathrm{Cl}_{2}$ in the lower stratosphere and $5 \%$ for $\mathrm{CH}_{4}, 10 \%$ for $\mathrm{N}_{2} \mathrm{O}$ and $\mathrm{CF}_{2} \mathrm{Cl}_{2}$ around $30 \mathrm{~km}$ altitude. It should be noted that the uncertainty such defined is a precision; it does not include a possible systematic deviation due to absolute calibration. As far as a comparison to modelled profiles is concerned this is no drawback, since those profiles are generally calculated using the measured mixing ratio at the earth's surface as boundary value which would be subject to the same shift in calibration. Thus to claim agreement a theoretical profile would have to lie within $\sigma / \sqrt{n_{i}}$ of the mean measured profile. This places quite narrow constraints on the model predicted vertical profiles.

Mean profiles of longlived trace gases of comparable quality are available at a number of locations and several seasons ( $\mathrm{cf}$. Ehhalt, 1980). As has been argued above, a mean profile at one location should be reasonably representative of the zonally averaged profile at that latitude. Thus some of the suggested quantitative testing is possible for 20 models. Paradoxically 10 models cannot be tested more rigorously because very few data are available in the tropics and those only in one season so that the required globally averaged vertical profiles and their uncertainty are not yet available for long lived trace gases.

Not all stratospheric trace species have been or can be measured with sufficient precision to exc?ude a significant contribution to the observed variance by instrumental uncertainties. Even worse, sometimes the uncertainties, which beset the stratospheric measurements, are difficult to identify by laboratory simulations alone. 
For thosecases, the present analysis, which also provides a base for independently estimating the natural variance, might prove a useful tool to identify or test experimental uncertainties. Some of the satellite observations or measurements of total $\mathrm{NO}_{y}$ or $\mathrm{ClO}_{y}$ are a point in case.

It is hoped that satellite data will expand the data base presently available. This would allow both, to obtain the globally averaged vertical concentration profiles and their uncertainties to test $1 \mathrm{D}$ models and to obtain $2 \mathrm{D}$ fields to test $2 \mathrm{D}$ models more extensively. Moreover it would provide $2 \mathrm{D}$ fields of the equivalent displacement height from which meridional fields of the transport parameters including $\overline{\alpha^{\prime 2}}$ could be derived for all seasons.

\section{Acknowledgement}

We would like to thank Dr. R.E. Dickinson, NCAR, Dr. A. Ebe1, University of Cologne and Dr. J. Mahlmann, GFDL, for helpful discussions. The work was sponsored by the German Ministry for Science and Technology. 


\section{References}

Attmannspacher, W. Sonderbeobachtungen des Meteorologischen Observatoriums Hohenpeißenberg Nr. 41 Ergebnisse der aerologischen und bodennahen Ozonmessungen im 2. Ha ibjahr 1979, Hohenpeißenberg 1980 Attmannspacher, W., Sonderbeobachtungen des Meteorologischen Observatoriums Hohenpeißenberg Nr. 42 Ergebnisse der aerologischen und bodennahen Ozonmessungen im 1. Halbjahr 1980, Hohenpeißenberg 1981

Cole, A.E. and A.J. Cantor, Air Force Reference Atmospheres, Air Force Surveys in Geophysics, No. 382, AGFL-FR-78-0051, 1978

Danielsen, E.F., An Objective Method for Determining the Generalized Transport

Tensor for Two Dimensional Eulerian Models, J. Atmos. Sci. 38, $1319-1339,1981$

Dickinson, R.E., Method of Parameterisation for Infrared Cooling between Altitudes of 30 and $70 \mathrm{Kilometers,} \mathrm{J.} \mathrm{Geophys.} \mathrm{Res.} \mathrm{78,} \mathrm{4451-4457,} 1973$

Diutsch, H.H., Atmospheric Ozone and Ultraviolet Radiation, World Survey of Climatology, 4 , Climate of the Free Atmosphere, D.F. Rex, Editor, E1sevier, 383-432, 1969

Dütsch, H.H., Vertical Ozone Distribution of a Global Scale, Pure Appl. Geophys . 116, 511-519, 1978

Ehhalt, O.H.; The Observation of Long-Lived Trace Gases in the Stratosphere, Proceedings of the Quadrennial International Ozone Symposium, Boulder, Colorado, 4-9 August 1980, 728-737

Fabian, P., R. Borchers, K.H. Weiler, U. Schmidt, A. Volz, D.H. Ehhalt, W. Seiler, and F. Muiller; Simultaneously Measured Vertical Profiles of $\mathrm{H}_{2}, \mathrm{CH}_{4}, \mathrm{CO}, \mathrm{N}_{2} \mathrm{O}, \mathrm{CFCl}_{3}$, and $\mathrm{CF}_{2} \mathrm{Cl}_{2}$ in the Mid-Latitude Stratosphere and Troposphere, J. Geophys. Res. 84, 3149-3154, 1979

Fabian, P., R. Borchers, G. Flentje, W.A. Matthews, W. Seiler, H. Gieh1, K. Bunse, F. Müller, U. Schmidt, A. Volz; A. Khedim, and F.J. Johnen; The Vertical Distribution of Stable Trace Gases of MidLatitudes, J. Geophys. Res. 86, 5179-5184, 1981 
Goldan; P.D., W.G. Kuister, D.L. Albritton, and A.L. Schmeltekopf; Stratospheric $\mathrm{CFCl}_{3}, \mathrm{CF}_{2} \mathrm{Cl}_{2}$, and $\mathrm{N}_{2} \mathrm{O}$ Height Profile Measurements at Several Latitudes, J. Geophys. Res. $85,413-423,1980$

Matsuno, T.; Lagrangian Motion of Air Parcels in the Stratosphere in the Presence of Planetary Waves, Pure App 1. Geophys. 118, 189-216, 1980

National Academy of Sciences, Environmental Impact of Stratospheric Fight, National Academy of Sciences, Washington, D.C., p. 124, 1975 Reed, R.J.," and K.E. German; A Contribution to the Problem of Stratospheric Diffusion by Large-Scale Mixing, Mon. Weather Rev. 93, 313-321, 1965

U.S. Standard Atmosphere, 1976, National Oceanic and Atmospheric Administration NOAA-S/T 76-1562

Volz, A., U. Schmidt, J. Rudolph, D.H. Ehhalt, F.J. Johnen, and A. Khedim; Vertical Profiles of Trace Gases at Mid-Latitudes, Berichte der Kernforschungsanlage Jülich, Nr. 1742, 1981 


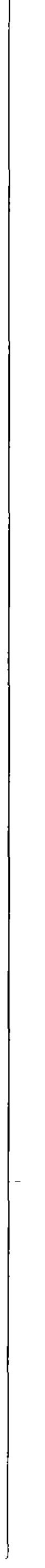




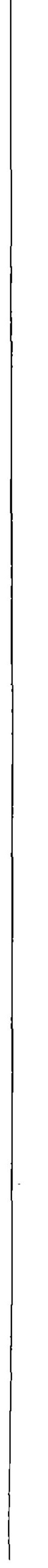

